\title{
Atypische serologische Befunde bei Paralyse und ihre Bedeutung.
}

\author{
Von \\ Privatdozent Dr. V. Kafka. \\ (Aus dem serologischen Laboratorium der Staatskrankenanstalt und psychiatrischen \\ Universitätsklinik Friedrichsberg in Hamburg.)
}

(Eingegangen am 19. November 1919.)

I.

Die Entwicklung der Serologie der Lues hat es uns ermöglicht, statistische UUberblicke über die Häufigkeit positiver WaR. in Blut und Rückenmarksflüssigkeit bei den verschiedenen Stadien und Formen der Syphilis zu gewinnen und in Verbindung mit den anderen Reaktionen typische Reaktionsbilder oder -profile aufzustellen. Dies gilt ganz besonders für die Spätlues des Zentralnervensystems. Konnten doch Nonne und seine Schüler auf Grund der Ergebnisse der ,,vier Reaktionen" ein Schema für die serologische Diagnostik dieser Gruppe einführen. Sie fanden in $100 \%$ der Fälle von Paralyse positive WaR. im Blute, wobei Holzmann ${ }^{9}{ }^{10}$ ) als Ausnahme angab, daß während interkurrenter Erkrankungen und in der Agonie die Wasser mann sche Reaktion negativ werden kann. In jüngster Zeit hat auch Es k u chen ${ }^{4}$ ) über $100 \%$ positive WaR. im Blute der Paralytiker berichtet. Die ,vier Reaktionen“ sind nach Nonne und Holzmann im Paralytikerliquor in rund $100 \%$ positiv (Lymphocytose $95 \%$ ). Auch Eskuchen ${ }^{4}$ ), um wieder diese neue Arbeit gegenüberzustellen, kommt zu ähnlichen Ergebnissen. Für die Lues cerebrospinalis wird von Non ne und $\mathrm{Holz}$ mann in $80-90 \%$ eine positive WaR. im Blute angenommen, von Eskuchen im akuten Stadium 70-80\%, im chronischen $60 \%$. Die Liquorreaktionen sind nach Nonne und Holzmann bei der erwähnten Erkrankung fast stets positiv (mit den bekannten Differenzen gegenüber der Paralyse). Eskuchen trennt mit Recht das akute vom chronischen Stadium ab; bei ersterem findet er so gut wie immer positive Reaktionen (WaR. 90\%) im Liquor, bei letzterem die WaR. in $70 \%$ der Fälle, die übrigen (,vier") Reaktionen fast immer positiv, wenn auch quantitativ viel schwächer als im akuten Stadium. Sowohl bei Nonne wie auch bei Eskuchen sehen wir also die WaR. für die Lues cerebri häufiger als positiv angegeben als im Blut, wobei natür- 
lich für die Rückenmarksflüssigkeit die Auswertungsmethode nach Hauptman $n^{7}$ ) in Betracht kommt, während im Blute bloß mit der Originaldosis gearbeitet wurde.

Es würde nach der Darstellung von Eskuchen den Anschein haben, als hätte sich seit der Aufstellung des Nonneschen Schemas bezüglich der Statistik der Häufigkeit der WaR. in Blut und Liquor nicht viel geändert. In Wirklichkeit aber haben viele Arbeiten der neueren Zeit [Rost ${ }^{34}$ ) u. a.] gezeigt, daß in jedem Stadium der Syphilis eine negative Blutreaktion bei noch bestehenden klinischen Erscheinungen und positiver WaR. im Liquor vorkommen kann. Besonders bezüglich der Spätlues des Zentralnervensystems sind nach dieser Richtung hin viele Einzelheiten bekannt geworden. Für die Paralyse haben schon $1906 \mathrm{Wassermann}$ und Plaut $\mathrm{t}^{39}$ ) sowie 1907 Plaut $\left.{ }^{30}\right)^{31}$ ) angegeben, daß die WaR. im. Liquor stärker als jene im Blute sein könne. Wassermann und Plaut fanden unter 5 Paralysen zweimal die WaR. im Liquor stärker als im Blut; Pla ut sah bei 15 vergleichenden Untersuchungen (Paralytiker) 4 mal im Liquor einen höheren Reagingehalt als im Blute. Die Autoren zogen aus diesem Verhalten den Schluß auf die Möglichkeit der lokalen Entstehung der Luesreagine. Durch die im Jahre 1911 von Ha u pt ma $n n^{7}$ ) eingeführte Auswertungsmethode wurde einerseits die Anzahl der im Liquor positiven Fälle von Spätlues vermehrt, andererseits aber die Vergleichsbasis etwas verschoben, da für das Serum ja nur die Einstellung von $0,1-0,2 \mathrm{ccm}$ in Frage kam. Auf diesen Punkt wird später noch einzugehen sein. Unter den damals von Hauptman $n^{7}$ ) berichteten Fällen zeigten unter 44 von Lues cerebri 12 eine negative Blutreaktion, während die WaR. im Liquor bei 5 in der Dosis $0,4 \mathrm{ccm}$, bei 5 in der Dosis $0,6 \mathrm{ccm}$, bei 2 in der Dosis $0,8 \mathrm{ccm}$ Liquor positiv war. Unter 6 Fällen von Paralyse fand sich eine, bei der die WaR. im Blute negativ, jene im Liquor bei $0,6 \mathrm{ccm}$ positiv war. Im Jahre 1913 hat $\mathrm{Kaf} \mathrm{ka}^{14}$ ) der zu gleicher Zeit wie Kromayr und Trinchese ${ }^{21}$ ) mit bis $0,5 \mathrm{ccm}$ steigenden Mengen des inaktiven Serums arbeitete, außerdem aber damals im Blut die Modifikation nach M. Stern, die Cholesterinkältemethode nach $J$ acobsthal, die Normalamboceptorabsorption nach $J$ a cob a e us und die Komplementoidabsorption nach Wechselmann ausführte und im Liquor die WaR. bis 1,0 auswertete, über eine Reihe von Paralysen berichtet, die bei negativer Originalreaktion nach Wassermann im Blute und negativen oder positiven Ergebnissen der Verfeinerungsmethoden eine positive WaR. im Liquor zeigten. Er konnte ferner bei einer Reihe von Paralysen, die stationär oder atypisch verliefen, ein allmähliches Schwächerwerden der Liquor- und Blutreaktionen verfolgen, wobei erstere in der Abnahme vorausgingen. $\mathrm{Neue} \mathrm{e}^{27}$ ) hat im Jahre 1914 berichtet, daß unter 13 Fällen von Lues des Zentral- 
nervensystems 3 waren, die eine negative WaR. im Blute bei positiver im Liquor boten. Ich gebe die Zahlen hier wieder:

Fall 1. I. Blut akt. u. inakt. bis 0,4 Liquor bei $0,4+$

II. Blut akt. u. inakt. bis 0,5 Liquor bei $0,2+$

Fall 6. Blut akt. u. inakt. bis 0,5 Liquor bei $0,4+$

Fall 11. Blut akt. u. inakt. bis 0,5 Liquor bei $0,4+$

Drei weitere Fälle, die schwankende Ergebnisse boten, seien hier nicht angeführt. Unter 5 Fällen von Paralyse boten zwei bei einzelnen Untersuchungen ein negatives Resultat. Hier ist zu berücksichtigen, da $\beta$ Ne ue das aktive und inaktive Serum bis $0,5 \mathrm{ccm}$ auswertete.

Ich habe hier nur einzelne wichtige Arbeiten, die vor dem Kriege entstanden sind, angeführt. Während des Krieges hat Kaf k $\mathrm{a}^{15}$ ) mehrmals darauf hingewiesen, da $\beta$ neben der Gehirnlues ganz besonders Paralysen vorkommen können, die bei glatt negativem Blutwassermann eine positive Reaktion des Liquor bieten; in solchen Fällen kamen vor der Vornahme der Lumbalpunktion diagnostische Mißgriffe vor. Wir werden daher an die Spitze unserer folgenden Untersuchungen die klinisch sichere Paralyse stellen, die bei glatt negativer WaR. im Blute eine positive Reaktion im Liquor bei $0,2 \mathrm{ccm}$ aufweist. Von diesem Phänomen aus werden wir auf die geringeren Differenzen zwischen Blut und Liquor eingehen. Dabei wird auch das Reaktionsbild des.Liquors, das ja ein für die Paralyse ungemein charakteristisches geworden ist, zu berücksichtigen sein.

Utber Paralysen mit negativen oder negativ werdenden Reaktionen in Blut und Liquor haben Jakob und $\mathrm{Kaf} \mathrm{ka}^{13}$ ) berichtet. Kaf ka ${ }^{14}$ ) hat ähnliche Fälle im Jahre 1913 mitgeteilt. Ne ue und Vorkast ner ${ }^{28}$ ) veröffentlichten folgenden Fall aus dem Jahre 1910: Typische Paralyse mit Tabessymptomen; Dauer $1 \mathrm{Jahr}$. Blut: WaR. $(0,2) \theta$; Liquor: WaR. $(0,2) \theta$ (nicht ausgewertet). Zellen 11, Ph. I stark positiv. Schönhals ${ }^{3 \pm a}$ ) beschrieb folgenden Fall: Sehr langsam fortschreitende Tabesparalyse mit negativer WaR. in Blut und Liquor bei positiver $\mathrm{Ph} I$ mit mittlerer Pleocytose. Binswanger ${ }^{2}$ ) teilte den Fall einer Tabesparalyse mit, die seit 1891 tabische Symptome aufwies; 1906 traten die ersten psychischen Defekte auf. Exitus 1910 oder 1911. Die WaR. war im Blut und Liquor negativ, ebenso Ph. I und Pleocytose. Die Sektion bestätigte die Diagnose. Ein zweiter ähnlicher Fall kam nicht zur Sektion. Forster ${ }^{5}$ ) erwähnt eine anscheinend typisch verlaufene und zur Sektion gekommene Tabesparalyse. Die WaR. im Blute war negativ, jene im Liquor bis 1,0 negativ, Ph. I und Pleocytose waren stark positiv. Die Sektion bestätigte die Diagnose. Auffallend ist, daß es sich bei diesen Fällen fast durchweg um Tabesparalysen handelt.

Es wird Sache der folgenden Auseinandersetzungen sein, den oben geschilderten serologischen Atypien der Paralyse nachzugehen und eventuelle Schlüsse aus den Ergebnissen zu ziehen. 
II.

A. Zur Beantwortung der Frage, wie häufig bei der Paralyse grobe Verschiedenheiten der WaR. in Liquor und Blut zuungunsten des letzteren vorkommen, haben wir das Paralysematerial unseres Laboratoriums aus zwei Arbeitsjahren herangezogen. Wir haben aber nur Fälle ausgesucht, bei denen Blut- und Liquorentnahme an demselben Tage ausgeführt worden war, um Titerdifferenzen zu vermeiden und beide Flüssigkeiten mit den gleichen Reagenzien und unter den gleichen Versuchsbedingungen untersuchen zu können.

Da nun die Technik der WaR. ja heute sehr verschieden gehandhabt wird, da sie aber für die Kritik der Ergebnisse von Bedeutung ist, so sei unsere Methodik im folgenden dargestellt, wobei auf die Tabelle I verwiesen wird.

Wir arbeiteten mit einer 5 proz. Hammelblutaufschwemmung, die ans dem defibrinierten Gesamtblut hergestellt war. Als Extrakt dienten uns in allen Fällen alkoholische Normalextrakte aus Menschenherzen, in der großen Mehrzahl der Fälle auch nach H. Sachs hergestellte Cholesterinextrakte (natürlich nur für das Blut). Gerade letztere spielen infolge ihrer starken Empfindlichkeit bei unserem Material eine Rolle (s. Fall 11 und 12 der Tabelle I). In vielen Fällen wurde auch mit einem. alkoholischen Luesleberextrakt aus der Tauentzienapotheke in Berlin gearbeitet. Die Extraktgebrauchsdosis war auf die gewöhnliche Art an einem großen Material bestimmt worden. Das Krankenserum wurde möglichst frisch verarbeitet und stets in der Menge von 0,2 und $0,5 \mathrm{ccm}$ (bezogen auf $5 \mathrm{ccm}$ Gesamtvolumen), der Liquor in den Dosen von 0,2, 05, und 1,0 cem (bezogen ebenfalls auf $5 \mathrm{ccm}$ Gesamtvolumen) angesetzt. Das Komplement wurde nicht austitriert; verwendet wurde $1 \mathrm{ccm}$ der $1 / 20^{-}$-Verdünnung (bezogen auf $5 \mathrm{ccm}$ Gesamtvolumen). Vor jedem Versuch wurde der Immunamboceptor antitriert, und es wurden 5 A.-E. Im Hauptversuch benutzt. Wegen der schwierigen Tierverhältnisse wurde neben halben Dosen auch in Viertelmengen (Gesamtvolumen 1,25 ccm) gearbeitet. Inaktivierungszeit und -art sowie alle anderen Faktoren schlossen sich eng der Originalmethode an. In allen Fällen wurde mit dem nicht inaktivierten Serum die Modifikation nach M. Stern vorgenommen, entsprechend den günstigen Erfahrungen, die wir seit langen Jahren mit dieser Methode gemacht haben. Die Bezeichnungen der Tabelle sind folgendermaßen zu verstehen:

$$
\begin{aligned}
+++ & =\text { stark positiv } \\
++ & =\text { mittelstark positiv, } \\
+ & =\text { positiv, } \\
(+) & =\text { schwach positiv, } \\
((+)) & =\text { Spur Hemmung, } \\
(((+))) & =\text { Spürehen Hemmung, } \\
\theta & =\text { negativ. }
\end{aligned}
$$

Es sei gleich angeführt, daß zur vollständigen Beantwortung unserer eingangs gegebenen Fragestellung es notwendig gewesen, sämtliche am gleichen Tage venae- und lumbalpunktierte Fälle von Paralyse in Blut und Liquor bis zur Titergrenze zu prüfen. Wir haben dies aber absichtlich unterlassen, da uns nicht daran lag, geringfügige Unterschiede in der Stärke der WaR., die ja käufig vorkommen und auch 
wechseln, festzustellen, sondern grobe, mit unserer gewöhnlichen Methodik feststellbare Differenzen, die allein zu theoretischer Verwertung berechtigen.

Die Rückenmarkst̉ủssigkeit wurde in den betreffenden Fällen noch weiter untersucht, soweit die Kriegsverhältnisse es gestatteten; zumindest wurden in jedem Falle die Zellen gezählt und die Phase I gemacht; in den meisten Fällen wurde die Mastixreaktion nach Jacobsthal und $\mathrm{Kafka}$ angestellt und in einigen die Hämolysinreaktion nach Weil und Kafka.

Wir fanden nun, wie Tabelle I lehrt, aus dem Material der 2 Jahre 24 zu gleicher Zeit venae- und lumbalpunktierte Fälle von Paralyse, die große Differenzen in bezug auf die WaR. in Blut und Liquor zuungunsten des ersteren zeigten. Da wir nun in der angegebenen Zeit abgesehen von Fall 7, der der neuesten Zeit angehört - 100 Paralysen, die an demselben Tage lumbal- und venaepunktiert waren und bei denen die WaR. in Blut und Liquor entweder gleich oder in der Rückenmarksflüssigkeit etwas schwächer oder im Blute nur geringfügig schwächer war, untersucht hatten, so können wir sagen, da $\beta$ bei der Paralyse in $18,7 \%$ der Fälle die Blutreaktion deutlich schwächer ist als jene der Rückenmarksflüssigkeit, und zwar im Serum so schwach, daß sie bei lediglicher Einschätzung der Originalreaktion als negativ gebucht werden muß.

Nun zu Einzelheiten der Tabelle I. Es handelt sich um klinisch typische Fälle; bei den sezierten ist die Diagnose Paralyse auch histologisch festgelegt. Die ersten 10 Fälle zeigen durchweg mit sämtlichen Extrakten negativen Ausfall der WaR. im Blute; Stern ist in diesen Fällen nur zweimal positiv (Fall 8 und 9), dreimal fast negativ (Fälle 6, 7 und 10), fünfmal negativ. Die WaR. im Liquor ist in dieser Gruppe sechsmal bei 0,2 positiv, einmal bei dieser Dosis zweifelhaft; bei 0,5 ist sie bis auf Fall 5 überall positiv. Die prägnantesten dieser Gruppe sind die Fälle 1, 2, 6, 7, 9 und 10. Fall 7 ist mehrmals untersucht; er hat stets das gleiche Resultat gegeben. Dieser Gruppe am nächsten stehen die Fälle 11 und 12, bei denen im Blute nur der Cholesterinextrakt einmal eine Andeutung (Fall 11), einmal deutlich Hemmung (Fall 12) zeigte bei negative $m$ Stern und stark positiven Liquorreaktionen. Es folgen dann die Fälle 13 und 14, bei denen wir im Blute nur eine Andeutung von Hemmung mit dem Luesleberextrakte sehen, bei 14 auch positiven Stern, während die WaR. im Liquor stark positiv ist. Sehr deutliche Differenzen im Verhalten der WaR. in Blut und Liquor zuungunsten des ersteren weisen dann weiter die Fälle 14 und 15 auf, denen sich die übrigen graduell anschließen. Auf die Verschiedenheit in der Reaktion mit differenten Extrakten bei der gleichen Flüssigkeit sei hier nicht eingegangen, da es sich ja nur um den Vergleich der Reaktionen mit den gleichen Extrakten und der gleichen Technik in Blut und Liquor handelt. 
Atypische serologische Befunde bei Paralyse und ihre Bedeutung. 265

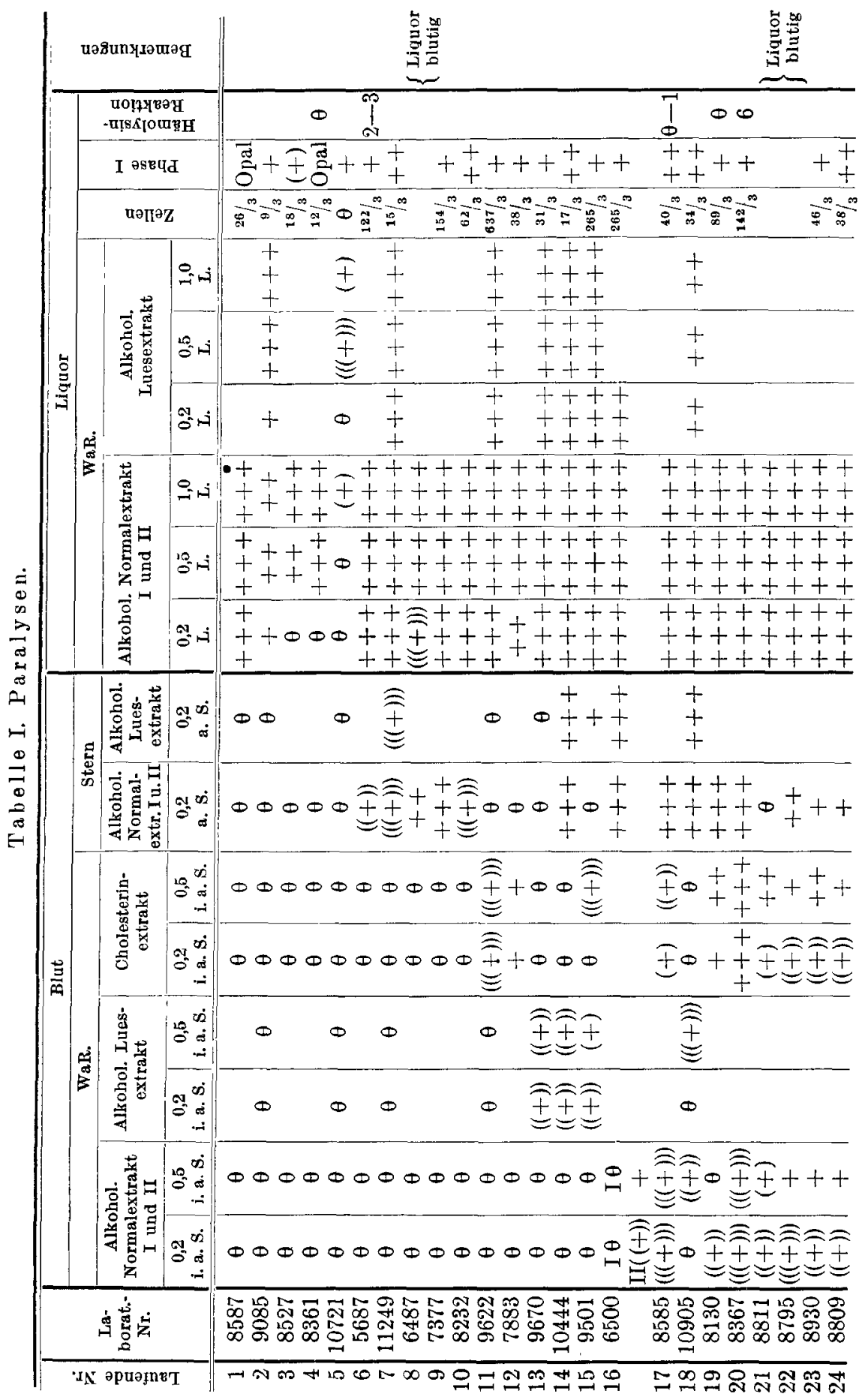


Bevor ich die Ergebnisse der Tabelle I zusammenfasse, möchte ich einen prominenten Fall ausführlicher bringen, es ist Nr. 6 der Tabelle.

Beobachtung 1. Landsturmm. Kon., aufgen. 15. III. 1917, entl. 2. IX. 1917.

Vorgeschichte: Die ersten Krankheitserscheinungen traten nach einer Verschüttung am 23. III. 1916 ein: Pat. war bewußtlos, kam nach 2 Stunden wieder zu sich. Im Kriegslazarett wurde konstatiert: linksseitige Amaurose und Anakusie, Abasie-Astasie, hemianopische Einengung des rechtsseitigen Gesichtsfeldes, Sensibilitätsstörung, aber auch Pupillendifferenz mit rechtsseitiger Lichtstarre, linksseitiger Lichtträgheit. Es wurde die Diagnose auf Gehirnerschütterung gestellt. Im Reservelazarett, wo sich die funktionellen Symptome besserten, wurde ebenfalls die Diagnose auf Gehirnerschü tterung gestellt. Im nächsten Reservelazarett wurde die Diagnose gestellt auf: Hirnverletzung, traumatische Neurose, Simulation. Da die Wa R. im Blut negativ war, hielt man auch die Pupillenstarre für simuliert, $d$. h. für durch Atropinmißbrauch hervorgerufen. K. mußte daher ein Uhrglas, das durch einen Gipsverband fixiert war, über dem Auge tragen. Da sich die Pupillenstörung trotzdem nicht besserte, erklärte man sie durch „Hirnblutung“ oder "Gehirnerschütterung“ entstanden. Die funktionellen Symptome traten allmählich in den Hintergrund. K. wurde als a. r. entlassen mit $30 \%$ Dienstbeschädigung wegen der Pupillenstörung. Wieder lazarettbedürftig geworden, wurde im Reservelazarett die Diagnose gestellt (es war wieder die Wa $\mathbf{R}$. im Blute negativ): nervöse Beschwerden nach Verschüttung. Er kam dann in die Korpsnervenstation Altona. Hier lautete die Diagnose: Schädigung der Regenbogenhautreflexe, Abwehrneurose

Bei der Aufnahme zeigte K. an körperlichen Erscheinungen: Pupille r. $>$ l., beide entrundet, r. schwache, 1. fehlende Lichtreaktion. Facialisdifferenz zuungunsten der $r$. Seite. PSR. sehr lebhaft, kein Fußklonus, kein Babinski. Paralytische Schrift. Es besteht ferner eine hysterische Lähmung des linken Armes und Beines, die aggraviert wird. Außerdem Cystititis.

Seelisch: Stumpf, interesselos, leicht dement, erregbar.

Blutbef und: WaR. mit allen Extrakten 0,2-0,5: negativ.

Stern: Schwach positiv, Normalamboceptorabsorption: bei $0,2++$. Reaktion nach Abderhalden: nur Andeutung von Abbau von Gehirnrinde.

Liqu orbefund: Klar, starker Druck.

Zellen $122 / 3$.

Phase I: $t$.

$40 \%$ Ammon-S.-Frakt.: Schwach + .

$33 \%$ Ammon-S.Frakt.: Opal.

WaR. $0,2++, 0,5+++$.

Hämolysinreaktion: + .

Mastixreaktion: Paralysenkurve.

Es handelt sich also hier um eine Paralyse kombiniert mit einer hysterischen Störung. Letztere trat nach der Verschüttung auf; auf die Ersterscheipungen der Paralyse ist man aber anscheinend erst nach der Verschüttung aufmerksam geworden, wenn sie nicht, wie es ja vorkommt, erst durch das Trauma manifest geworden sind. Die negative WaR. im Blute hat hier bewirkt, daß nicht nur an der richtigen Diagnose vorbeigegriffen wurde, sondern daß man für die Pupillenstörung alle mögliche Faktoren als ursächlich annahm (Simulation, Gehirn- 
blutung, Gehirnerschütterung, Schädigung der Regenbogenhäute) und die übrigen Erscheinungen der Paralyse übersah. Außerdem wurden auch Konsequenzen auf Dienstfähigkeit und Druckbeschädigung gezogen.

Wir können also zusammenfassen, daß bei der typischen Paralyse in ungefähr rund $20 \%$ der Fälle, die am gleichen Tage venae- und lumbalpunktiert wurden, die WaR. eine negative oder fast negative war bei positiver Reaktion der Rückenmarksflüssigkeit.

Es könnte nun gegenüber unseren Feststellungen eingewendet werden, daß die oben beschriebenen Verhältnisse nur Erscheinungen eines Stadiums waren, d. h. daß die angeführten Paralysefälle in ihrer Gesamtzahl oder teilweise jener größeren Kategorie von Fällen angehören, bei denen die Tendenz zum Negativwerden der Reaktionen der Körperflüssigkeiten, vor allem der biologischen, besteht. Dazu ist zu bemerken, daß, wie verschiedene Fälle zeigen, das in der Tabelle niedergelegte Ergebnis ein ständiges ist, d. h. daß die Liquorreaktionen in typischen Paralysefällen nicht zum Negativwerden neigen. Dagegen ist die negative oder fast negative Blutreaktion, die nicht wieder positiv wird, das Endergebnis des Negativwerdens einer früher positiven WaR. In welche Zeit dieser Umschlag fällt, läßt sich für unser Material nicht sagen.

B. Von den bisher besprochenen Paralysefällen sind daher jene zu trennen, bei denen neben der Blutreaktion a uch die Liquorreaktion schon negativ ist oder unter unseren Augen wird. Wị haben schon an anderer Stelle ${ }^{13}$ ) solche Fälle besprochen und gezeigt, daß diese biologischen Phänomene meist mit Atypien im klinischen Verhalten und oft überraschendem anatomisch-biologischem Gehirnbefund einhergehen. Wir haben hier deswegen nur Fälle herangezogen, die histologisch genau untersucht worden sind. Bei der Wichtigkeit solcher Fälle erschien uns eine ausführlichere Wiedergabe notwendig.

Bezüglich der Technik der Blut- und Liquoruntersuchung muß hier noch einiges zu dem früher Gesagten hinzugefügt werden, da die Fälle größtenteils aus der Friedenszeit stammen. Es wurde häufig die Cholesterinkältemethode nach Jacobsthal ausgeführt, da sie uns als empfindliche Verfeinerung der WaR. auch auf Grund eigener Erfahrungen bekannt war. In einzelnen Fällen wurde auch, um alle Verfeinerungen im Blute auszuprobieren, die Normalamboceptorabsorption nach Jacobaeus, sowie die Komplementoidabsorption nach Wechselmann angesetzt. Ferner wurde der Normalamboceptor und das Eigenkomplement des Krankenserums in der von $\mathrm{Kaf} \mathrm{ka}^{16}$ ) angegebenen Form mehrmals bestimmt, da eine Herabsetzung dieser hämolytischen Komponenten bei der Spätsyphilis, zumal der Paralyse, nicht selten ist. Neben der Phase I wurde manchmal auch die fraktionierte Ammoniumsulfataussalzung nach Kafka ausgeführt. Daneben wurden öfter die Globulinreaktionen nach Pandy, Noguchi und Braun- Husler an- 
gesetzt und das Gesamteiweiß nach Nissl oder Brandberg - Zaloziecki bestimmt. Außerdem wurde in einigen Fallen die Goldsolreaktion nach C. Lange gemacht*).

Unser Material besteht aus 10 Fällen.

\section{a) Serologisch negative, klinisch als Paralyse diagnosti- zierte Fälle.}

Beobachtung 2. Pr., aufgen. am 18. VII. 1913, geboren 1868.

Syphilitische Infektion in der Militärzeit. Beginn der Erkrankung nicht mit Sicherheit festzustellen. Somatisch: Pupillen stark verzogen, $1 .>$ r., Lichtreaktion wenig ausgiebig. Facialisdifferenz $1 .<$ r. PSR, gesteigert. Romberg + . Artikulatorische Sprachstörung. Psychisch: dement, verwirrt, motorische Unruhe, erhebliche Störung der Merkfähigkeit, erregt.

Exitus in Krämpfen am 8. X. 1913.

Blutbefund vom 23. VII. 1913.

WaR. bis $0,5 \theta$.

Stern: $\theta$.

Cholesterinkältemethode: $\theta$.

Normalamboceptor- und Komplementgehalt: Normal.

Liquorbefund vom 23. VII. 1913:

Zellen: $3 / 3$.

Phase I: Schwach + .

Fraktion. Ammoniumsulfataussalzung: $\theta$.

Pandy: Schwach + .

Noguchi: Schwach + .

Braun-Husler: $\theta$.

Gesamteiweiß (Nissl): ${ }^{1 / 2}$ Teilstrich $=0,0085 \%$.

WaR. bis $1,0: \theta$.

Hämolysinreaktion: $\theta$, Komplement: $\theta$.

Goldsol: $1 / 10-1 / 160$ violett, $1 / 320-1 / 640$ rotviolett, von $1 / 1280$ an rot.

Histologischer Befund (Prosektor Dr. Jakob): Endarteriitis syphilitica der kleinen Hirnrindengefäße.

Beobachtung 3. Mar., aufgen. am 14. IV. 1906, geboren 1863.

Anamnese: Früher Klagen über Schwindel und Kopfstiche, 1898 plötzlich die Sprach ,,weggeblieben“. Seit 1905 häufige Sprachstörungen; zunehmende Erregung und Gedächtnisschwäche, Vergiftungsideen. Somatisch (April 1906): Pupillen gleich, mittelweit, Reaktion auf Licht l. träge und wenig ausgiebig, r. fehlend. Romberg +. Gang ataktisch. Schrift paralytisch. Artikulatorische Sprachstörung. Psychisch: desorientiert, einsichtlsos, Größenideen, motorisch unruhig, kindisch, verwirrt. Zeitweise angeblich Sinnestäuschungen akustischer Natur und Andeutung von Wahnideen. Die Demenz schreitet vorwärts; der Kranke wird ruhig, stumpf, mit deutlicher Sprachstörung.

Exitus nach körperlichem Verfall seit 1916 am 8. III. 1917.

Blutbefund am 4. VII. 1913:

WaR. bis $0,5: \theta$.

Stern: + .

Normalamboceptorabsorption: $((+))$.

*) Die Technik der obgenannten Reaktionen ist genau beschrieben bei Kaf ka, Taschenbuch der praktischen Untersuchungsmethoden der Körperflüssigkeiten bei Geistes- und Nervenkrankheiten. Julius Springer. Berlin 1917. 
Baryumsulfat: $\theta$.

Cholesterinkältemethode: $\theta$.

Normalamboceptor, Komplement: Normal.

Liquorbef und am 4. VII. 1913:

WaR. bis $1,0: \theta$.

Zellen $8 / 3$.

Phase I: Opal. 40 proz. Fraktion: Opal.

Pandy: + .

Noguchi: $\theta$.

Braun-Husler: $\theta$.

Hämolysinreaktion: $\theta$, Komplement: $\theta$.

His tologischer Befund (Prosektor Dr. Jakob): Typischer Befund der stationären Paralyse mit einem abgeheilten Gumma in einem Putamen.

Beobachtung 4. Hey., 1. Aufnahme 6. I. 1905, 2. Aufnahme 19. III. 1906, geboren 1869 .

Anamnese: Syphilitische Infektion 1894 oder 1896. Sensibler Jackson Februar 1904. Im Eppendorfer Krankenhaus vom 19. III. 1904 bis 3. V. 1904 wegen somatischer und psychischer Symptome; dort wurde Paralyse diagnostiziert und eine Quecksilberkur vorgenommen. Nachher weitere Intelligenzabnahme.

Somatisch (7. I. 1905): Pupillen prompte Lichtreaktion, Facialisdifferenz, Vibrieien der Mundmuskulatur. PSR. sehr gesteigert, Ataxie, Schrift paralytiseh, Sprache artikulatorisch gestört.

Psychisch: Hochgradige Intelligenzstörung, Apathie, starke Demenz, zeitweise erregt.

14. VIII. 1905 gebessert entlassen.

Zwischenzeit: Sehr stumpf, unsauber.

Somatisch (März 1906): Wie früher, starke Sprachstörung. 1904 Pupillen-eaktion auf Licht sehr gering.

Psychisch: Zeitweise apathisch, dann wieder motorisch sehr erregt. Verlauf: Fortschreitende Demenz. November 1913: Tuberkulinbehandlung ohne jeden Erfolg. 1915: Ganz verblödet, unsauber, Sprache unverständlich.

29. IX. 1916. Exitus an Marasmus.

Tabelle 2. Blut- und Liquorbefunde der Beobachtung 4.

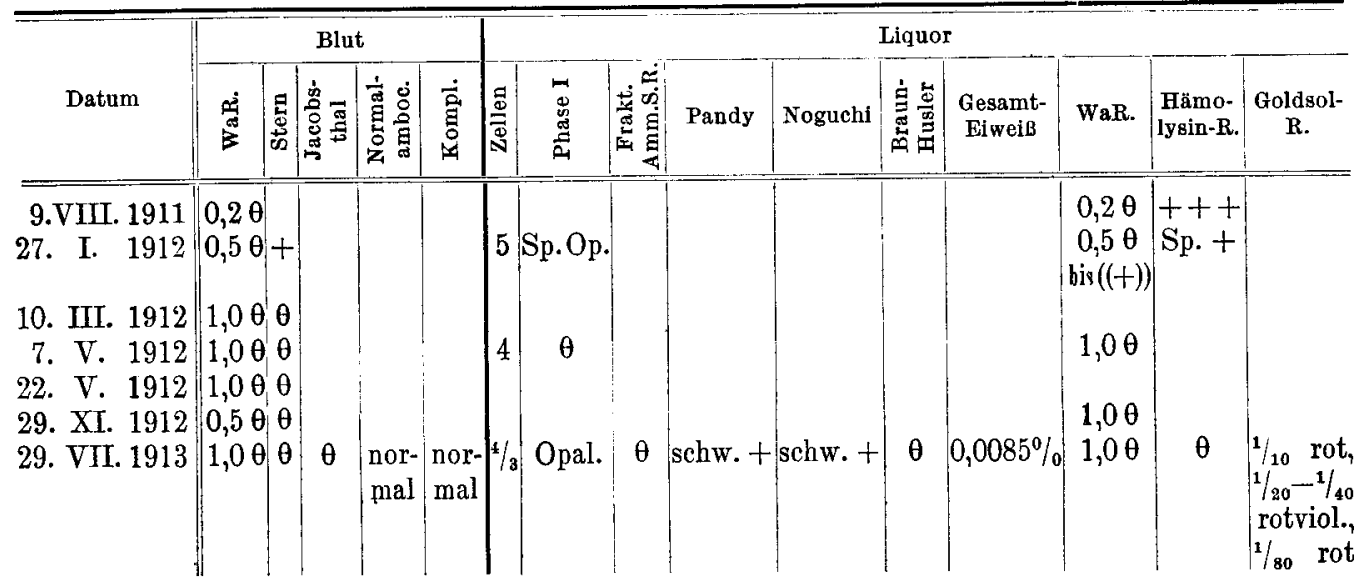


Die histologische Untersuchung konnte nicht vorgenommen werden, da die Sektion untersagt worden war.

Epikrise: Die Beobachtung 2 mußte klinisch als Paralyse gedeutet werden; die Dauer war kurz; histologisch erwies sie sich auffallenderweise als syphilitische Endarteriitis. Beobachtung 3 zeigte klinisch das typische Bild der stationären Paralyse von langer Dauer, auffallend waren nur Halluzinationen und angebliche Wahnideen. Hier ergab die histologische Untersuchung tatsächlich das Bestehen einer stationären Paralyse, wobei freilich Reste einer Gehirnlues vorhanden waren. Bei Beobachtung 4 war ebenfalls klinischerseits eine langdauernde (12 Jahre) stationäre Paralyse anzunehmen; leider konnte die Diagnose durch die histologische Untersuchung nicht bestätigt werden, da die Sektion verweigert worden war.

b) Serologisch negativ werdende, klinisch als Paralysen diagnostizierte Fälle.

Beobachtung 5. Kau., aufgen. 22. VII. 1909, geboren 3. V. 1873.

Anamnese: Im Krankenhause Eppendorf vom 15. bis 19. VII. 1909. Dort wurde Paralyse diagnostiziert wegen somatischer und psychischer Symptome. Infektion negiert.

Somatisch: Pupillen r. $>$ l, Lichtreaktion gering, artikulatorische Sprachstörung, lebhafte Reflexe. Psychisch: Dement, stumpf, euphorisch, leicht erregbar.

Im weiteren Verlauf stumpf, katatone Züge, maniriert.

1. III. 1911 intravenöse Salvarsanbehandlung begonnen.

17. XI. 1913 bis 16. I. 1914 Tuberkulinbehandlung. Keine Besserung. Verblödet, stumpf, hinfällig.

4. XII. 1915 Exitus an Marasmus.

Tabelle 3. Blut- und Liquorbefunde der Beobachtung 5 .

\begin{tabular}{|c|c|c|c|c|c|c|c|c|c|c|c|}
\hline \multirow[b]{2}{*}{ Datum } & \multirow[b]{2}{*}{$\begin{array}{c}\text { Kranken- } \\
\text { haus }\end{array}$} & \multicolumn{2}{|c|}{ Blut } & \multicolumn{8}{|c|}{ Liquor } \\
\hline & & WaR. & Stern & $\mid$ & Phase I & $\begin{array}{l}\text { Frakt. } \\
\text { Ammon. } \\
\text { S. Auss }\end{array}$ & Pandy & $\mid \begin{array}{l}3 \\
0 \\
0 \\
0 \\
0 \\
0 \\
0\end{array}$ & 高惫 & WaR. & 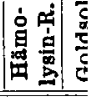 \\
\hline MitteJuli1909 & Eppendorf & $\theta$ & & + & + & & & & & $\theta(0,2)$ & \\
\hline 23. XI. 1910 & Friedrichsb. & $\theta(0,5)$ & & $\theta$ & $\theta$ & & & & & $\theta(1,0)$ & \\
\hline 3. XII. 1910 & Eppendorf & & & & & & & & & $\theta(1,0)$ & \\
\hline 20. I. 1911 & Friedrichsb. & & & & & & & & & $\boldsymbol{\theta}(0,2)$ & \\
\hline & & & & & & & & & & $\begin{array}{c}+(0,0) \\
+++(1,0)\end{array}$ & \\
\hline 1. III. 1911 & $m$ & $((+))(0, \overline{0})$ & $+t+$ & & & & & & & $++(0,4)$ & \\
\hline 26. I. 1913 & $n$ & $\begin{array}{l}((+))(0,2) \\
++(0,4) \\
+++(0,6)\end{array}$ & $t+t$ & $8 / 3$ & $\theta$ & & & & & $\begin{array}{c}((+)))(0,2) \\
(+)(0,4) \\
++(0,6)\end{array}$ & 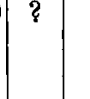 \\
\hline 19. V. 1913 & & & & & Sp.Op. & & $\theta$ & $\theta$ & & $\theta(0,5)$ & $\theta$ \\
\hline 29. VII. 1913 & $\pi$ & $+(0,5)$ & $\theta$ & & Sp. Op. & $\begin{array}{r}40^{\circ} \% \\
\text { Sp. Op }\end{array}$ & schw. + & $\theta$ & $\theta$ & $\boldsymbol{\theta}(1,0)$ & \\
\hline
\end{tabular}


Atypische serologische Befunde bei Paralyse und ihre Bedeutung. 271

Histologischer Befund (Prosektor Dr. Jakob): Leichte Erscheinungen der Paralyse im ganzen Zentralnervensystem, nur spurweise angedeutet; Infiltrationen sehr gering ausgesprochen, ebenso Meningitis. Parenchymerkrankung deutlich. (Typischer Befund einer stationären Paralyse.)

Beobachtung 6. Pet., aufgen. 16. IX. 1908, geboren 1867.

Anamnese: Deutliche Heredität. Mehrere Frühgeburten. Anfang September 1908 Verkehrtheiten gemacht, erregt, Gedächtnisschwäche, stumpf, verstimmt. 13. IX. 1908 bis 16. IX. 1908 im Eppendorfer Krankenhaus. Somatisch: Gesicht schlaff innerviert, Zittern der Zunge, Pupillen r. $>1$, prompte Lichtreaktion, lebhafte Reflexe, artikulatorisehe Sprachstörung. Psychisch: Euphorisch, albern, dement, Gedächtnisschwäche. Weiterer Verlauf: Immer stumpf, oft erregt, dement.

12. III. 1912 Pupillen $r$. $>$ l. Lichtreaktion r. schwach, 1. fehlend. 5. V. 1912 paralytischer Anfall. 13. V. 1912 Exitus.

Tabelle 4.

\begin{tabular}{|c|c|c|c|c|c|c|}
\hline \multirow{2}{*}{ Datum } & \multicolumn{2}{|c|}{ Blut } & \multicolumn{3}{|c|}{ Liquor } & \\
\hline & WaR. & Stern & Zellen & Phase I & WaR. & \\
\hline $\begin{array}{rll}\text { 19. } & \text { IX. } 1908 \\
\text { 2. } & \text { III. } 1910 \\
\text { 6. } & \text { IV. } 1910 \\
\text { 20. } & \text { II. } 1912 \\
\text { 13. } & \text { V. } 1912\end{array}$ & $\stackrel{+}{+}$ & $t+t$ & $\begin{array}{c}++ \\
+\end{array}$ & $\begin{array}{l}+ \\
+\end{array}$ & $\begin{array}{c}+(0,2) \\
+ \\
\theta(1,0)\end{array}$ & Ventrikelliquor WaR. $\theta(1,0)$. \\
\hline
\end{tabular}

Histologischer Befund (Prosektor Dr. Jakob): Endarteriitis syphilitica der kleinen Hirnrinden- und Pialgefäße mit akuten Infiltrationserscheinungen, die zwischen Paralyse und Lues cerebri stehen.

Beobachtung 7. Ho., aufgen. 3. VI. 1899, geboren 1853.

Anamnese: 1895 aus einem Geschäfte ausgeschieden, weil es nicht mehr „,mit ihm ging". Februar 1896 wurde völlige Abnahme der Willenskraft konstatiert. Daher Aufnahme in die Armenanstalt. Dort (Werk- und Armenhaus) angeblich „epileptische" Krämpfe, Beziehungs- und Beeinflussungsideen. Seit Mai 1899 Stimmenhören, Verfolgungsideen. Somatisch: Pupillen ungleich, 1. > r., 1. prompte Lichtreaktion, r. fast lichtstarr. Facialis r. $>1$. Psychisch: Erregt, akustische Halluzinationen, Beziehungsideen, Wortneubildungen, stumpf, interesselos. 1905 deutliche Demenz, Wahnideen treten zurück, Halluzinationen scheinen noch zu bestehen. 1910. Wird ,belästigt", oft erregt, aber stumpf, dement. 18. IX. 1911 Gehirnpunktion und Balkenstich. 31. VII. 1913. Linke Pupille lichtstarr, rechte Spur Reaktion. Gesteigerte Reflexe. Facialis r. $>$ I. Sehr stumpf, Wortneubildungen. 26. XII. 1914. Paralytischer Anfall. 1915 sehr dement. Dezember: Kurzdauernde Anfälle. 1916 Amaurose. Exitus 28. VII. 1916.

Histologischer Bef und (Prosektor Dr. Jakob): Ausgesprochene Paralyse mit schweren Parenchymdegenerationen und mäßig starken Infiltritationsvorgängen. 
Tabelle 5. Blut. und Liquorbefunde der Beobachtung 7.

\begin{tabular}{|c|c|c|c|c|c|c|c|c|c|c|c|}
\hline \multirow[b]{2}{*}{ Datum } & \multicolumn{3}{|c|}{ Blut } & \multicolumn{7}{|c|}{ Liquor } & \multirow[b]{2}{*}{$\underset{\text { merkunge }}{\mathrm{Be-}}$} \\
\hline & WaR. & Stern & $\begin{array}{c}\text { Jacobs- } \\
\text { thal }\end{array}$ & 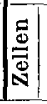 & Phase I & 焉 & 官总 & WaR. & 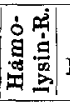 & $\begin{array}{c}\text { Goldsol- } \\
\text { Reaktion }\end{array}$ & \\
\hline $\begin{array}{r}\text { 2. IV. } 1910 \\
\text { 25. XI. } 1910 \\
\text { 9.VIII. } 1911 \\
\text { 18. IX. } 1911\end{array}$ & $\begin{array}{c}++ \\
++ \\
+ \\
+\end{array}$ & & & + & $\begin{array}{l}+ \\
+\end{array}$ & 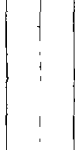 & & $\begin{array}{c}+++(0,2) \\
++(0,2) \\
+(0,2) \\
+(0,2)\end{array}$ & & & \\
\hline 16. X. 1911 & $+++(0,2)$ & +++ & & 6 & Opal & & & $\left\{\begin{array}{l}(+)(0,2) \\
+(t) 5)\end{array}\right.$ & & & \\
\hline 17. IX. 1912 & & & & $3 / 3$ & $\theta$ & $\begin{array}{l}1 \\
1 \\
1\end{array}$ & & $\theta(1,0)$ & $\theta$ & & $\begin{array}{c}\text { Ventrike } \\
\text { liquor }\end{array}$ \\
\hline 4. X. 1912 & $+++(0,2)$ & $+t+$ & & & schw. + & ' & & $\left\{\begin{array}{c}\theta(0,2) \\
+(0,4)\end{array}\right.$ & & & \\
\hline 29. VII. 1913 & $+++(0,2)$ & ++ & +++ & $2 / 3$ & + & $+1+$ & $\theta$ & $\theta(1,0)$ & $\theta$ & $\left\{\begin{array}{l}1 / 10-1 / 40 \\
\text { rotviol., } \\
1 / 80 \text { bis } z\end{array}\right.$ & \\
\hline 2. II. 1916 & $+++(0,2)$ & & & & Sp.Op. & & & $\theta(1,0)$ & & & $\begin{array}{l}\text { Mastix-I } \\
\text { Lueszacl }\end{array}$ \\
\hline
\end{tabular}

Beobachtung 8. Hell., aufgen. 7. IX. 1910, geboren 1877.

Anamnese: In den letzten Jahren nervös, aufgeregt. In den letzten Tagen Größenideen. Keine Frühgeburten der Frau. Somatisch: Pupillen r. $>1$, 1. entrundet, lichtstarr; r. fast rund, Spur Lichtreaktion. Vibrieren der Mundmuskulatur. Reflexe lebhaft. Geringes Zittern der Hände. Artikulatorische Sprachstörung. Motorische Unruhe. Psychisch: Größenideen, Merkfähigkeit erheblich gestört, einsichtslos.

29. XI. 1910 Salvarsan intravenös, ebenso 31. XII. 1910. Klinisch unverändert Größenideen, euphorisch, dement. 8. IV. 1912 Exitus.

Tabelle 6. Blut-und Liquorbefunde der Beobachtung 8.

\begin{tabular}{|c|c|c|c|c|c|c|}
\hline \multirow{2}{*}{ Datum } & \multicolumn{2}{|c|}{ Blut } & \multicolumn{3}{|c|}{ Liquor } & \multirow{2}{*}{ Bemerkungen } \\
\hline & WaR. & Stern & Zellen & Phase I & WaR. & \\
\hline $\begin{array}{r}\text { 26. XI. } 1910 \\
\text { 29. XII. } 1910 \\
\text { 8. IV. } 1912\end{array}$ & $\begin{array}{l}++(0,2) \\
+(0,2)\end{array}$ & ++ & $\begin{array}{r}60 \\
12 \\
2\end{array}$ & $\begin{array}{c}+ \\
+++ \\
\theta\end{array} \mid$ & $\begin{array}{c}+(0,2) \\
+++(0,2) \\
\theta(1,0)\end{array}$ & $\begin{array}{l}\text { Liquor sof. nach dem } \\
\text { Tode entnommen. }\end{array}$ \\
\hline
\end{tabular}

Histologischer Befund (Prosektor Dr. Jakob): Paralyse, Spirochäten im Gehirn positiv.

Beobachtung 9. Pil., 1. Aufnahme 21. XI. 1907, 2. Aufnahme 26. VIII. 1908, geboren 1866 .

Anamnese: maniakalische Erregung, Größenideen, verwirrt. 2. Mann hatte Lues. Somatisch: Pupillen $\mathbf{r} .=1$, gute Reaktion auf Licht, PSR. lebhaft, Hypalgesie, Andeutung von Sprachstörung. Psychisch: Sehr erregt bettflüchtig, geschwätzig, blühende Größenideen, gewalttätig. Entlassen 5. II. 1908. In der Zwischenzeit unverändert, Größenideen. Somatisch: Pupillen l. $<$ r., l. gute 
Atypische serologische Befunde bei Paralyse und ihre Bedeutung. 273

Lichtreaktion, r. sehr gering. PSR. lebhaft. Psychisch: Größenideen, euphorisch, dement apathisch, zeitweise sehr erregt; später leichte Remission.

1910 hinfällig dement, unsauber. Enesolbehandlung. 8. XII. 1911 Exitus.

Tabelle 7. Blut-und Liquorbefunde der Beobachtung 9.

\begin{tabular}{|c|c|c|c|c|c|c|}
\hline \multirow[b]{2}{*}{ Datum } & \multicolumn{2}{|l|}{ Blut } & \multicolumn{4}{|c|}{ Liquor } \\
\hline & WaR. & Stern & Zellen & Phase I & WaR. & $\begin{array}{l}\text { Hämo- } \\
\text { lysin-R. }\end{array}$ \\
\hline 26. VIII. 1910 & $+++(0,2)$ & +++ & 8 & + & $\begin{array}{c}((+))(0,2) \\
+++(0,4)\end{array}$ & \\
\hline 17. VII. 1911 & $+(0,2)$ & + & 60 & + & $+++(0,2)$ & \\
\hline 5. IX. 1911 & $+++(0,2)$ & $++t$ & 32 & + & $\theta(1,0)$ & $\theta$ \\
\hline 25. X. 1911 & $+++(0,2)$ & $++t$ & 3 & + & $\theta(1,0)$ & $\theta$ \\
\hline
\end{tabular}

Histologischer Befund (Prosektor Dr. Jakob): Endarteriitis der, kleinen Hirnrindengefäße und stellenweise Meningitis syphilitica.

Beobachtung 10. Det., aufgen. 8. VIII. 1913, geboren 1873.

Anamnese: Seit Juli 1912 Erscheinungen. Somatisch: Pupillen leicht entrundet, Lichtreaktion wenig ausgiebig, Facialislähmung, Zunge weicht nach rechts ab. Reflexe lebhaft. Artikulatorische Sprachstörung. Psychisch: Ängstlich, desorientiert, rechnet schlecht, geistiger Niedergang. Verlauf: Stumpf, hinfällig, angeblich Sinnestäuschungen, Andeutung katatonischer Bewegungen. August 1914 Tuberkulinkur. 25. III., 17. IV. und 1. V. 1914: Endolumbale Salvarsaninjektionen. Keine klinische Besserung. 1915: Unverändert. 8. III. 1916 Exitus.

Tabelle 8. BIut-und Liquorbefunde der Beobachtung 10.

\begin{tabular}{|c|c|c|c|c|c|c|c|c|c|c|c|}
\hline \multirow[b]{2}{*}{ Datum } & \multicolumn{3}{|c|}{ Blut } & \multicolumn{8}{|c|}{ Liquor } \\
\hline & WaR. & Stern & $\begin{array}{l}\text { Hämo- } \\
\text { lysine }\end{array}$ & 胥 & 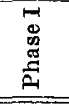 & 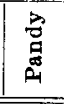 & $\mid \begin{array}{c}3 \\
0 \\
0 \\
0 \\
0 \\
2\end{array}$ & 离昜惫 & WaR. & 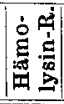 & $\begin{array}{l}\text { Goldsol-R. } \\
\text { und } \\
\text { Bemerkungen }\end{array}$ \\
\hline 11.VIII. 1913 & $+++(0,2)$ & $++t$ & $\begin{array}{l}\text { herab- } \\
\text { gesetzt }\end{array}$ & $62 / 3$ & + & ++ & + & & $+++(0,2)$ & $\theta$ & $\begin{array}{l}\text { Paralysenkurve. } \\
\text { Fraktionierte Am- } \\
\text { moniumsulfat } \\
\text { aussalzung 40\% } \\
+, 33 \% \text { Opal. }\end{array}$ \\
\hline 24. III. 1914 & $+++(0,2)$ & +++ & herab- & $60 / 3$ & ++ & & & & $+++(0,2)$ & $\theta$ & \\
\hline 18. IV. 1914 & $+++(0,2)$ & +++ & herab- & $24 / 3$ & Opal- & & & & $\theta(0,2)$ & $\theta$ & \\
\hline 1. V. 1914 & $\theta(0,2)$ & +++ & normal & 5 & $f+$ & & & $1 / 4 \%$ & $\theta(0,2)$ & $\theta$ & \\
\hline
\end{tabular}

Histologischer Befund (Prosektor Dr. Jakob): Typische, weit vorgeschrittene Paralyse.

Beobachtung 11. Kalk., aufgen. 2. V. 1913, geboren 1876 .

Somatisch: Erscheinungen der Paralyse. Psychisch: Demenz, erregt, stumpf, anscheinend Wahnideen (?). Im Verlaufe sehr viele paralytische Anfälle. November 1913 Tuberkulinkur. 24. III., 17. IV. und 1. V. 1914 endolumbale Salvarsaninjektionen. Keine klinische Besserung. 27. VIII. 1914 Exitus.

Histologischer Befund (Prosektor Dr. Jakob): Endarteriitis syphilitica mit paralytischer Meningitis und leichten Infiltrationserscheinungen. 
Tabelle 9. Blut- und Liquorbefunde der Beobachtung 11.

\begin{tabular}{|c|c|c|c|c|c|c|c|c|}
\hline \multirow[b]{2}{*}{ Datum } & \multicolumn{4}{|c|}{ Blut } & \multicolumn{4}{|c|}{ Liquor } \\
\hline & WaR. & Stern & $\begin{array}{c}\text { Jacobs- } \\
\text { thal }\end{array}$ & \begin{tabular}{|l|} 
Hämo- \\
lysine
\end{tabular} \mid & Zellen & $\begin{array}{c}\text { Ph. } \\
\text { I }\end{array}$ & WaR. & $\begin{array}{l}\text { Hämo- } \\
\text { lysin-R. }\end{array}$ \\
\hline $\begin{array}{l}\text { Mai } 1913 . \\
\text { 24. IIT. } 1914 \\
\text { 17. IV. } 1914 \\
\text { 1. V. } 1914\end{array}$ & $\begin{array}{l}+++(0,2) \\
+++(0,2) \\
+++(0,2) \\
((+))(0,2)\end{array}$ & $\begin{array}{l}+++ \\
+++ \\
+++\end{array}$ & $\left|\begin{array}{c}++ \\
+++ \\
+++\end{array}\right|$ & normal & $45 / 3$ & & $\begin{array}{c}+++(0,2) \\
+++(0,2) \\
+++(0,2) \\
++(0,2)\end{array}$ & ++ \\
\hline
\end{tabular}

Ich möchte, bevor ich auf die Epikrise der eben dargestellten Fälle eingehe, zweier gedenken, die ich selbst größtenteils beobachtet habe und die jetzt noch in Behandlung stehen. Sic weisen das Interessante auf, daß unter unseren Augen beim Stationärwerden des Prozesses die Liquor- und Blutreaktionen negativ werden.

Beobachtung 12. Schm., aufgen. 8. III. 1916, geboren 1887.

Anamnese nicht zu erheben. Mit Attest wegen beginnender Paralyse überwiesen. Somatisch: Pupillen l. > r., Lichtreaktion 1. vollkommen fehlend, r. Spur. Differenz der Nasenlippenfalten zuungunsten der linken Seite. Zittern der Zunge und der vorgestreckten Hände. Reflexe lebhaft. Sehr starke artikulatorische Sprachstörung. Psychisch: Stumpf, dement, euphorisch, interesselos. Stationäres Verhalten. 17. IV. 1918. Herpes zoster. 19. IV. 1919 Pupillen 1. > r. lichtstarr. Silbenstolpern. PSR. lebhaft. Dement.

Tabelle 10. Blut- und Liquorbefunde der Beobachtung 12.

\begin{tabular}{l||c|c|c|c|c|c}
\hline \hline \multirow{2}{*}{ Datum } & \multicolumn{2}{|c|}{ Blut } & \multicolumn{3}{|c|}{ Liquor } & \multirow{2}{*}{ Bemerkungen } \\
\cline { 2 - 5 } & WaR. & Stern & Zellen & Phase I & WaR. & \\
\hline 15. III. 1916 & $+(0,2)$ & & $60 / 3$ & schw. + & $++(0,5)$ & \\
4. IX. 1918 & $\theta(0,5)$ & $\theta$ & & & & \\
22. IV. 1919 & $\theta(0,5)$ & ++ & $3 / 3$ & Opal & $\theta(1,0)$ & $\begin{array}{c}\text { Carcolidreaktion (J a cobs - } \\
\text { thal): negativ. }\end{array}$ \\
22. VII. 1919 & $\theta(0,5)$ & $(((+)))$ & $3 / 3$ & Opal & $\theta(1,0)$ &
\end{tabular}

Beobachtung 13. Reb., aufgen. 21. XII. 1914, geboren ${ }^{-1} 880$.

Anamnese: 1899 apoplektischer Insult. Seit 1912 dement, Dezember 1914 angeblich wieder leichter apoplektiformer Anfall. Status (22. XII. 1914): Somatisch: Pupillen r. $>1$, beide entrundet, sehr geringe Lichtreaktion, leichte linksseitige motorische Lähmung. Artikulatorische Sprachlähmung. Sehnenreflexe 1. > r. Psychisch: sehr dement, erregt, desorientiert. Verlauf: Extremitätenlähmung geht schnell zurück. Dement. Februar 1915 Gesichtserysipel. Später stationäres Bild mit typischen Zugen der Paralyse. September 1918 ganz kleine Anfälle, bei denen sie einnäßt.

Tabelle 11. Blut-und Liquorbefunde der. Beobachtung 13.

\begin{tabular}{r||c|c|c|c|c}
\hline \hline \multicolumn{1}{|c||}{ Datum } & \multicolumn{2}{|c|}{ Blut } & \multicolumn{3}{|c}{ Liquor } \\
\hline \hline $\begin{array}{l}\text { WaR. } \\
\text { 25. II. 1915 }\end{array}$ & Stern & Zellen & Phase I & WaR. \\
4. IX. 1918 & $\theta(0,5)$ & $\theta$ & $65 / 3$ & ++ & $+++(0,2)$ \\
23. IX. 1919 & & $5 / 3$ & Opal & $\begin{array}{r}\theta(0,5) \\
+(1,0)\end{array}$
\end{tabular}


Atypische serologische Befunde bei Paralyse und ihre Bedeutung. 275

Bevor wir nun die anatomisch untersuchten Fälle epikritisch betrachten, möchte ich der Übersichtlichkeit halber die Ergebnisse tabellarisch zusammenstellen. Beobachtung 11 kommt dabei vorläufig nicht in Betracht, da bei ihm ein deutliches Negativwerden der serologischen Reaktionen nicht $\mathrm{zu}$ beobachten ist.

Tabelle 12. Zusammenfassung der Gruppen a und b.

\begin{tabular}{|c|c|c|c|c|c|}
\hline \multirow{2}{*}{ ن } & \multirow{2}{*}{ Klínische Díagnose } & \multirow{2}{*}{ Dauer } & \multicolumn{2}{|c|}{ Serologische Befunde } & \multirow{2}{*}{$\begin{array}{c}\text { Histologisch } \\
\text { (Prosektor Dr. J a kob) }\end{array}$} \\
\hline & & & Blut & Liquor & \\
\hline 2 & Paralyse & 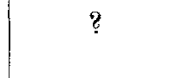 & Negativ & $\begin{array}{l}\text { Negativ (bis auf Glo- } \\
\text { buline) }\end{array}$ & $\begin{array}{l}\text { Endarteritis syphili- } \\
\text { tica. }\end{array}$ \\
\hline 3 & $\begin{array}{l}\text { Stationäre Paralyse } \\
\text { (Andentung von } \\
\text { Sinnestäuschungen } \\
\text { und Wahnideen) }\end{array}$ & $\begin{array}{l}12 \text { Jahre. } \\
\text { Prodromaler - } \\
\text { scheinungen } \\
\text { schon früher }\end{array}$ & $\begin{array}{c}\text { Negativ(Stern } \\
+)\end{array}$ & Negativ & $\begin{array}{l}\text { Stationäre Paralyse } \\
\text { mit einem abgeheil- } \\
\text { ten Gumma im } \mathrm{Pu}- \\
\text { tamen. }\end{array}$ \\
\hline 4 & Stationäre Paralyse & 12 Jahre & $\begin{array}{l}\text { Negativ(Stern } \\
\text { anfänglich } t)\end{array}$ & $\begin{array}{l}\text { Negativ (Hämolysin- } \\
\text { reaktion anfänglich } \\
+ \text { ) }\end{array}$ & Nicht seziert. \\
\hline 5 & $\begin{array}{l}\text { Stationäre Paralyse } \\
\text { (mit katatonen Zü- } \\
\text { gen) }\end{array}$ & 6 Jahre & $\begin{array}{l}\text { Erst negativ, } \\
\text { dann schw. } \\
\text { positiv }\end{array}$ & $\begin{array}{l}\text { Erst negativ (bis auf } \\
\text { Zellen und Ph. I), } \\
\text { dann positiv, dann } \\
\text { wieder negativ (bis } \\
\text { auf Globuline) }\end{array}$ & Stationäre Paralyse. \\
\hline 6 & Paralyse & 4 Jahre & $\mid \begin{array}{r}\text { Erst positiv } \\
\text { dann negativ } \\
(\text { Stern }+++)\end{array}$ & $\begin{array}{l}\text { Erst positiv, dann } \\
\text { negativ, Ventrikel- } \\
\text { liquor negativ }\end{array}$ & $\begin{array}{l}\text { Endarteriitis syphili- } \\
\text { tica mit Infiltrati- } \\
\text { onen, die zwischen } \\
\text { Paralyse und Lues } \\
\text { cerebri stehen. }\end{array}$ \\
\hline 7 & $\begin{array}{l}\text { Stationüre Paralyse } \\
\text { (m. Sinnestäuschun- } \\
\text { gen u. Wahnideen, } \\
\text { Anfälle) }\end{array}$ & 19-20 Jahre & Positiv & $\begin{array}{l}\text { Erst positiv, dann all- } \\
\text { mählich negativ (bis } \\
\text { auf Globuline) }\end{array}$ & $\begin{array}{l}\text { Ausgesprochene } \mathrm{Pa}- \\
\text { ralyse mit schweren } \\
\text { Parenchymdegene- } \\
\text { rationen und mäßig } \\
\text { starker Infiltration. }\end{array}$ \\
\hline 8 & $\begin{array}{l}\text { Paralyse (intravenöse } \\
\text { Salvarsanbehand- } \\
\text { lung) }\end{array}$ & 2 Jahre & $\begin{array}{c}\text { Positiv m.Nei- } \\
\text { gung zur Ab- } \\
\text { schwächung }\end{array}$ & $\begin{array}{c}\text { Erst negativ, sofort } \\
\text { posmortem negativ }\end{array}$ & Paralyse. \\
\hline 9 & $\begin{array}{l}\text { Paralyse (Enesol- } \\
\text { behandlung) }\end{array}$ & 3 Jahre & Positiv & $\begin{array}{l}\text { Erst positiv, dann } \\
\text { negativ (bis auf Glo- } \\
\text { buline) }\end{array}$ & $\begin{array}{l}\text { Endarteriitis syphili- } \\
\text { tica, stellenweise } \\
\text { Meningitis syphili- } \\
\text { tica. }\end{array}$ \\
\hline 10 & $\begin{array}{l}\text { Paralyse (Andeutung } \\
\text { vonSinnestäuschun- } \\
\text { gen und katatonen } \\
\text { Bewegungen, Tu- } \\
\text { berkulin- und endo- } \\
\text { lumbale Salvarsan- } \\
\text { behandlung) }\end{array}$ & $1 \mathrm{Jahr}$ & $\begin{array}{r}\text { Zuerstpositiv } \\
\text { dann negativ }\end{array}$ & $\begin{array}{l}\text { Erst positiv, dann } \\
\text { negativ (bis auf Glo- } \\
\text { buline) }\end{array}$ & $\begin{array}{l}\text { Typische, weit vor- } \\
\text { geschrittene Para- } \\
\text { lyse. }\end{array}$ \\
\hline
\end{tabular}


Wenn wir nun die Beobachtungen 5-10 epikritisch betrachten, so sehen wir die histologische Diagnose einer-einfachen Paralyse in Beobachtung 8 gestellt. Dem entsprach auch das klinische Bild und die Liquorreaktionen intra vitam. Wieso sofort nach dem Tode die Rückenmarksflüssigkeit ein vollkommen negatives Resultat aufwies, ist uns nicht ganz erklärlich. Das agonale Negativwerden der WaR. gilt nur für das Blut, nicht aber für den Liquor; ferner wissen wir, daß post mortem Zell- und Globulingehalt des Liquors schnell zunimmt. Leider ist nach der zweiten Salvarsaninjektion keine intravitale Lumbalpunktion gemacht worden, doch ist nicht wahrscheinlich, daß der Liquorbefund von April 1912 eine Folge der intravenösen Salvarsanbehandlung im November und Dezember 1911 ist. Hinter dieses Ergebnis ist also ein Fragezeichen zu setzen. Den Befund einer stationären Paralyse mit frischen Schüben zeigt histologisch die Beobachtung 7. Die Hirnpunktion im Jahre 1912 hatte wesentliche Infiltrationen vermissen lassen. Das klinische Bild war das einer stationären Paralyse, wobei aber Halluzinationen und Wahnideen vorhanden waren und auch - seit 1914 - Anfälle bestanden. Während die WaR. im Blute positiv blieb, wurden die Liquorreaktionen immer schwächer, schließlich bis auf geringe Globulinveränderungen (Mastix: Lueszaske) negativ. Wir kennen ein solches Schwächerwerden der Liquorreaktionen bei der stationären Paralyse (siehe auch Beobachtungen 12 und 13), nur wird hier meist auch der Blutbefund negativ. Den bei der Sektion nachgewiesenen Infiltrationserscheinungen im Gehirn entspricht kein Aufflackern der entzündlichen Liquorerscheinungen; vielleicht wären solche bei einer Lumbalpunktion nach Februar 1913 nachzuweisen gewesen oder noch später, wenn der Kranke am Leben geblieben wäre. Hier besteht also eine stationäre Paralyse mit klinischen Atypien. Diesem Falle reiht sich Beobachtung 5 an. Hier zeigte sich histologisch der typische Befund der stationären Paralyse. Das klinische Bild bot durch katatone Züge eine gewisse Atypie. Hier ist als serologische Besonderheit zu vermerken, daß die Blut- und Liquorreaktion nach Wassermann zuerst negativ war. Sie wurde dann im Blute schwach positiv und blieb es, während sie im Liquor positiv und dann wieder negativ wurde. Es muß hier um die Wende der Jahre 1910 und 1911 zu einem neuen akuten Schub gekommen sein, worauf sich dann wieder die Tendenz zum Stationärwerden des klinischen Bildes und Negativwerden der serologischen Reaktionen (unterstützt vielleicht durch die Salvarsan- und Tuberkulinbehandlung) gezeigt hat. Bei Beobachtung 6 stand histologisch das Bild der Endarteriitis syphilitica im Vordergrund, zu der paralyseähnliche Infiltrationen kamen. Klinisch war eine 4 Jahre dauernde Paralyse ohne Atypien anzunehmen. Die zuerst positiven Blut- und Liquorreaktionen wurden schließlich negativ. Beobachtung 9 
wies histologisch die Zeichen der Endarteriitis syphilitica und stellenweise der Meningitis syphilitica auf, ohne daß etwas von Paralyse zu finden war. Klinisch bot die 3 Jahre dauernde Erkrankung die typischen Zeichen der Paralyse. Die serologischen Reaktionen im Blute waren positiv geblieben, die Liquorreaktionen bis auf $\mathrm{Ph}$. I negativ geworden. Bei Beobachtung 10 sehen wir ein Negativwerden der Reaktionen in Liquor und Blut im Falle einer typischen kurzdauernden Paralyse. Als Ursache müssen wir die Behandlung, vor allem die endolumbale Salvarsankur ansehen, bei der eine solche Beeinflussung des Liquors - wenn auch vorübergehend - nicht seltcn ist.

Wir können also durch Zusammenfassung des Materials der Gruppe B des II. Teils unter Berücksichtigung der Fälle, über die Jakob und Kafka im Jahre 1913 in Altona berichtet haben, sagen, daß Paralysefälle, die negative oder negativ werdende serologische Reaktionen in Liquor und Blut bieten, häufig auch klinische Atypien in Form von katatonen Zügen, Wahnideen und Sinnestäuschungen zeigen, doch kann die einfach verla ufende stationäre Paralyse ebenfalls mit negativen oder negativ werdenden Liquor- und Blutreaktionen einhergehen. Bei dieser kann durch akute Krankheits- (Spirochäten-) Schübedas klinische und histologische Bild im Sinne frischer Attacken verändert werden, wobei sich das Liquorbild den neuen Veränderungen anpassen kann, aber nicht muß. In Mischfällen von Lues cerebri und Paralyse hält sich Art und Verlauf der Liquorreaktionen an die überwiegende Krankheitsform, doch gibt uns Klinik und Serologie nicht immer eindeutige Resultate. Klinisch anscheinend sichere Paralysen, wobei klinische Atypien keineswegs vorliegen müssen, mit negativen oder negativ werdenden Liquorreaktionen können sich als Gehirnlues (Endarteriitis syphilitica der kleinen Hirnrindengefäße, Meningitis syphilitica) entpuppen. Da die Globulinreaktion der Rückenmarksflüssigkeit fast immer positiv bleibt, auch wenn die übrigen Reaktionen negativ werden, so kann ein verfeinerter Nachweis derselben (fraktionierte Ammoniumsulfataussalzung, Kolloidreaktionen) oft in solchen Fällen noch differentialdiagnostische Bedeutung haben. Die WaR. im Blute kann sowohl bei der stationären Paralyse wie bei der Endarteriitis s y philitica positivbleiben, negativ werden oder zur Zeit der Untersuchung schon negativ sein. Bei den im Blute und Liquor negativ werdenden Fällen scheint die WaR. der Rückenmarksflüssigkeit jener im Blute in der Abschwächung vorauszugehen. 
Greifen wir nun noch einmal auf den serologischen Normaltyp der Paralyse zurück. Er ist dann gegeben, wenn 1 . bei positiver WaR. im Blute sämtliche Liquorreaktionen positiv sind, wobei aber intensivster WaR. schwache oder mittelstarke entzündliche Reaktionen gegenüberstehen (von den Hämolysin- und den Kolloidreaktionen, die an sich für die Paralyse charakteristische Resultate ergeben, sei der Einfachheit halber abgesehen); 2. diese Reaktionen sich in allen Stadien der Krankheit ungefähr gleich bleiben; 3. wesentliche Veränderungen der Ergebnisse und ihre relativen Beziehungen auch durch die bisherigen Behandlungsmethoden (von der endolumbalen Salvarsanbehandlung abgesehen, siehe Beob. 10) nicht erzielt werden. Wir können nun auf Grund unserer Beobachtungen eine Reihe von Abweichungen feststellen. In rund $20 \%$ der Fälle von klinisch sicherer typischer Paralyse steht eine negative oder fast negative Blutreaktion normal positiven Liquorreaktionen gegenüber; in einer größeren Reihe von Paralysefällen ist die Differenz zuungunsten des Blutbefundes geringer, viele zeigen eine deutliche Tendenz zur Abschwächung der WaR. im Serum. Dabei ist, wie gesagt, der Liquorbefund normal und nur selten schwächer als in der Norm. Dieses Verhalten scheint deshalb praktisch noch wenig gewürdigt zu sein, weil Fälle mit negativer oder fast negativer WaR. im Blute, wie Beobachtung 1 so deutlich zeigt, oft nicht als Paralysen diagnostiziert werden und viele Ärzte dann auch nicht die Indikation für die Lumbalpunktion ansehen; natürlich mit vollem Unrecht, wie unsere Fälle zeigen, deren Bekanntmachung ja im Interesse der frühzeitigen Erkennung der Paralyse liegt. - Wenn aber auch die Rückenmarksflüssigkeit die Tendenz zur Abschwächung ihrer Reaktion zeigt oder diese schon negativ sind, wobei in einem Teil der Fälle auch die Blutreaktionen die gleiche Veränderung aufweisen, dann haben wir entweder stationäre Paralysen vor uns, die häufig auch atypische klinische Erscheinungen bieten, oder wir müssen selbst bei klinischem typischem Paralysenbefund an eine Endarteriitis der kleinen Hirnrindengefäße denken, da ja andere Formen der Gehirnsyphilis, die auch mit negativen Blut- und Liquorreaktionen einhergehen, ein von dem der Paralyse genügend differenzierbares klinisches Bild bieten. Wenn wir nun berücksichtigen, daß durch die feineren Eiweißdifferenzierungsmethoden der Rückenmarksflüssigkeit sich oft auch noch differentialdiagnostische Verschiedenheiten zwischen stationärer Paralyse und Endarteriitis syphilitica ergeben werden, dann können wir wohl sagen, daß durch unsere Feststellungen unsere bisherige serologische Diagnostik der Paralyse nicht beeinträchtigt, sondern im Gegenteil auf festeren Boden gestellt wird. 


\section{III.}

Vor der weiteren Diskussion der Ergebnisse des II. Teiles ist die Beantwortung einer Reihe von Fragen notwendig. Vor allem: Sind die Ergebnisse der WaR. in Blut und Liquor überhaupt vergleichbar? Diese Frage hat Zaloziec ki ${ }^{43}$ ) angeschnitten, auf Grund von Untersuchungen von $U$. Friede $\operatorname{man} n^{6}$ ). über die WaR. verschiedener Eiweißfraktionen des Serums und ihre gegenseitige Beeinflussung. Friedeman $n^{6}$ ) hatte festgestellt, daß die Globuline des normalen Serums die WaR. bieten, daß aber diese Komplementbindung im normalen Serum durch die Wirkung des Albumins aufgehoben wird. Dieses Verhältnis der Globuline und Albumine zueinander ist bei der Syphilis verändert: Die Globuline syphilitischer Sera werden durch die Albumine in ihrer komplementbindenden Wirkung nicht beeinträchtigt. Zaloziecki betont nun im Anschluß an diese Ergebnisse, daß es bei der WaR. einer Körperflüssigkeit auf das Verhältnis der die Komplementverbindung fördernden und hemmenden Substanz zueinander in ihr ankommen. Man könne daher die Stärke der WaR. nicht nach dem Ergebnis der Hämolysehemmung mit der betreffenden Flüssigkeit einschätzen und daraus auf die Menge der, ,Reagine“" schließen; insbesondere seien Blut und Liquor nach dieser Richtung nicht vergleichbar, da die Verhältnisse für das Zustandekommen der WaR. in der Rückenmarksflüssigkeit besonders günstig lägèn. Zaloziec ki legt also das Hauptgewicht auf der verschiedenen kolloidchemischen Zustand beider Flüssigkeiten. Es schien uns nun von Wichtigkeit, diese Annahme Zaloziec kis experimentell zu prüfen. Es mußte also, untersucht werden, wie die Eiweißfraktionen des normalen und pathologischen Liquors sich einzeln und kombiniert in bezug auf Komplementbindung verhalten. Da Globuline im normalen Liquor nur in geringer Menge vorhanden sind, war ihre Prüfung schwierig.

Die Technik der Versuche war auch deshalb nicht leicht, da meist nur kleine Liquormengen zur Verfügung standen, die Albumin- und Globulinmengen des Liquors gegenüber jenen des Blutes gering sind und in ihren Eigenschaften von jenen des Serums abweichen. Wir gingen nun im allgemeinen so vor, da $\beta$ wir in graduierten Zentrifugierröhrchen Liquor und konzentrierte Ammoniumsulfatlösung mischten ( $\overline{\mathrm{aa}}$ zur Fällung der Serumglobuline, in anderen Konzentrationen zur Fällung anderer Globuline), mehrere Stunden bei Zimmertemperatur stehen ließen und dann scharf zentrifugierten. Die Globuline setzten sich dann in der Spitze des Zentrifugierröhrchens fest und die überstehende Flussigkeit ließ sich gut und vollkommen abheben. Der Rückstand wurde nun, wenn Globuline gefällt waren, zweimal mit gesättigter Ammoniumsulfatlösung gewaschen (nach der Fällung der Euglobuline durch $1 / 3$ Sättigung mit Ammoniumsulfatlosung erfolgte die Waschung mit $2 / 3$ gesättigter Ammoniumsulfatlösung), dann in wenig 0,9 proz. NaCl-Lösung gelöst und in Dialysierhülsen 597a in kleinen Erlenmeyerkölbchen, die Zu- und Abfluß hatten, mindestens 24 Stunden gegen flieBendes Wasser dialysiert. Nach dieser Zeit wurde nun der Hülseninhalt gemessen; da er die Liquormenge, von der man ausgegangen war, fast immer überschritt, wurde nicht eingeengt, wie 
U. Friedemann es tut, sondern nach Besalzung wurde die Flüssigkeit so zur WaR. angesetzt, daß die Mengen der in den cinzelnen Röhrchen enthaltenen Körper den gebräuchlichen Liquormengen entsprachen; dabei wurde ein etwaiges Plus an Flüssigkeit allen Röhrchen des Versuches entsprechend zugesetzt und auch der native Liquor in gleicher Weise behandelt. Die überstehende Flüssigkeit mußte je nach der Versuchsart verschieden bearbeitet werden; hatte man die Gesamtglobuline durch Halbsättigung mit konzentrierter Ammoniumsulfatlösung gefällt, so waren in der Flüssigkeit nur die Albumine enthalten, es konnte also mindestens 24 Stundel. gegen fließendes Wasser, wie oben beschrieben, dialysiert werden; waren aber durch $1 / 3$ Sättigung mit konzentrierter Ammoniumsulfatlösung z. B. nur die Euglobuline entfernt, in der überstehenden Flüssigkeit also noch die „Pseudoalbumine“, wie Friede mann sie nennt (Pseudoglobulin, Serumglobulin und Albumin) enthalten, so mußte gegen fließende 0,9 proz. NaCl-Lösung dialysiert werden, um sämtliche Eiweißfraktionen in Lösung zu erhalten. Alles Weitere erfolgte wie oben. Einzelheiten sind a. a. O. nachzulesen, da der hier zur Verfügung stehende Platz es nicht gestattet, ausführlich über die Technik zu berichten.

Unsere Ergebnisse waren nun folgende. Die Globuline positiver*) Rückenmarksflüssigkeiten geben eine stark positive WaR. ohne Selbsthemmung, jene negativer Liquores zeigen meist negative, selten schwach positive WaR. Es verhalten sich also die Globuline positiver Rückenmarksflüssigkeiten genau wie die Globuline positiver aktiver Sera, die ja nach Friedemanns Versuchen und unseren Nachprüfungen stets ohne Selbsthemmung stark positiv reagieren. Die Globuline negativer Liquores unterscheiden sich in ihrer Wirkung nicht wesentlich von den Globulinen negativer aktiver Sera, die entweder (schwächer) Komplement ablenken oder auch mit Extrakt antikomplementär wirken oder aber beides vermissen lassen (U. Friedemanns Versuche). Wir freilich fanden in unseren Versuchen stets schwach positive Reaktion der Globuline des negativen aktiven Serums. Der - geringe Unterschied in der Wirksamkeit der Globuline negativer aktiver Sera und Liquores kann darin liegen, daß ja sicher negative Rückenmarksflüssigkeiten sehr wenig Globuline enthalten, kann also ein rein quantitativer sein. Hier sei nicht weiter auf diesen Punkt eingegangen; für unsere Zwecke genüge die wichtige Feststellung, daß sich die Globuline von Rückenmarksflüssigkeiten mit positiver WaR. in bezug auf Komplementbindung ebenso verhalten wie die Globuline, die wassermannpositiven aktiven (und auch inaktivierten) Seren entstammen. Bezüglich der Globuline wassermannnegativer Liquores besteht gegenüber dem aktiven Serum nur ein geringer Únterschied.

Untersuchten wir nun auch die Albumine des Liquors - wie auch jene des aktiven Serums - isoliert auf ihr Verhalten bezüglich der WaR., so fanden wir, daß die Albumine des positiven Liquors entweder

*) Der Kürze und Einfachheit halber ist in der folgenden Auseinandersetzung für wassermannpositiv positiv und für wassermannnegativ negativ gesagt. 
nicht Komplement binden oder Hemmung mit leichter Autotropie*) geben, jene des negativen Liquors boten hingegen starke Selbsthemmung. Bezüglich der aktiven Sera ist zu berichten, daß die Albumine, die positiven Flüssigkeiten entstammten, Autotropie boten, jene negativer Sera keine Einwirkung auf das Komplement besaßen.

Kombinierten wir nun, wie U. Friedemann es getan hat, um die Einwirkung der Albumine auf die Globuline zu studieren, so konnten wir die Angaben des eben genannten Forschers dahin bestätigen, daß die Wirkung der Globuline des positiven aktiven Serums weder durch die Albumine positiven noch durch jene negativen Serums aufgehoben wird, während es der Fall bei den Globulinen ist, die dem wassermannnegativen Serum entstammen. Bei der Kombination der Liquorglobuline und -albumine wurde dieses Phänomen nicht immer sichtbar, häufiger war Additionswirkung, doch war meist zu bemerken, daß eine Abschwächung der Wirkung der Globuline auftrat, die wassermannpositivem Liquor entstammen. Kombinierte man nun Liquorglobuline und Serumalbumine, so wurde ebenfalls die Wirkung der Globuline des positiven Liquors durch die Albumine sowohl des positiven wie des negativen aktiven Serums beeinflußt, aber immer im Sinne der Abschwächung der komplementbindenden Kraft; bei der Ko m bination mitAlbuminen verhalten sich alsodie Globuline positiver Rückenmarksflüssigkeiten nicht genau so wie jene, die positivem aktivem Serum entstammen, sie sind ihnen unterlegen. Die Globuline, die aus negativen Rückenmarksflüssigkeiten hergestellt sind, geben ja meist isoliert keine WaR., so daß bei Kombination mit Albuminen meist nur die Autotropie der letzteren zutage tritt.

Wir wollen die Konsequenzen dieser Feststellungen nicht weiter verfolgen, auch a. d. O. auf die Versuche nicht eingehen, die die Isolierung anderer Globulinfraktionen (Eu-, Pseudoglobuline) betreffen. Zur Beantwortung unserer eingangs gestellten Frage genügen die angeführten Ergebnisse. Aus ihnen geht hervor, daß Zalozieckis Annahme, die Verhältnisse für die WaR. lägen im Liquor besonders günstig, wenn man das Verhalten der Albumin- und Globulinfraktion zueinander zugrunde legt, sich nicht stützen läßt. Wir haben gesehen, daß die Globuline die positiven Rückenmarksflüssigkeiten entstammen, sich zwar isoliert wie jene des positiven Serums verhalten, daß erstere aber durch AlbumineinfluB in ihrer komplementbindenden Wirksamkeit beeinträchtigt werden, letztere nicht. Die Verhältnisse liegen nach dieser Richtung für den Liquor ungünstiger und Zalozieckis durch eigene Versuche nicht gestützte Betrachtungen sind nicht zutreffend. Wenn wir also, wozu wir in diesen Zeilen ja fortwährend ge-

*) Autotropie $=$ Selbsthemmung. 
nötigt sind, die WaR in Serum und Liquor eines Falles vergleichen, so müssen wir nicht befürchten, daß die Reagine im Liquor deutlicher zur Geltung kommen. Da es sich nun bei den unter II. A. behandelten Fällen um solche handelt, die im Liquor eine positive, im Serum eine negative WaR. bieten, so werden sich die Verhältnisse eher zugunsten der Differenz zwischen Liquor und Serum verschieben.

Als Anhang möchte ich einer Versuchsreihe kurz Erwähnung tun, die ich mit einem Serum angestellt habe, das im Blute nach Wassermann glatt negativ reagierte, im Liquor stark positiv. Das gleiche Ergebnis hatte sich bei mehreren Untersuchungen ergeben. Es ist Fall 7 der Tabelle 1. Die Globuline des aktiven Serums ergaben nur einmal positive WaR.; diese wurde durch Hinzufügung der eigenen Albumine aufgehoben. Wenn man nun zu den Globulinen des aktiven Serums die Albumine eines fremden positiven Serums hinzufügt, so wurde die komplement. bindende Wirkung aufgehoben, durch Kombinierung mit den Albuminen eines fremden negativen aktiven Serums hingegen wurde die WaR. der Globuline nun abgeschwächt. Solche Sera nehmen also eine Mittelstellung zwischen positiven und negativen Seren ein, stehen aber letzteren bedeutend näher.

Wir kommen nun, nachdem wir festgestellt haben, daß ein Vergleich der WaR. in Blut und Liquor gestattet ist, zu einer weiteren Frage: ist unsere Technik der WaR. geeignet, uns ein klares Bild der Reaktionsfähigkeit der Sera und Liquores im komplementbindenden Sinn zu geben? Hierzu müssen wir weiter ausholen. Bekanntlich sind zu der Originalreaktion nach v. Wasser ma n $\mathbf{n}$, die sich im Laufe der Jahre ja auch wesentlich verändert hat, eine große Reihe von Modifikationen hinzugekommen. Fast alle Faktoren, die bei der WaR. eine Rolle spielen, sind hierbei verändert worden, so Zustand und Menge des Krankenserums, Dauer und Art der Inaktivierung, Beschaffenheit und Dosis sowie Herstellungsart der Extrakte, Dosis des Komplements und des hämolytischen Immunserums, Darstellung der Hammelblutaufschwemmung, schließlich Aufbau, zeitliche Dauer und Aufeinanderfolge der Vorversuche und Teilversuche, die Versuchstemperatur u. v. a. Wir wollen uns hier nur mit drei wichtigen Faktoren beschäftigen: der Dosis des Krankenserums, der Komplementmenge und der Art der Herstellung. der Hammelblutaufschwemmung.

Von Kromayr und Trinchese ${ }^{21}$ ) und früher schon von uns ${ }^{14}$ ) wurde die Verwendung von $50 \%$ Krankenserum neben den üblichen $20 \%$ als Verfeinerung empfohlen. Neben vielen Autoren, die mit Erfolg so arbeiten, haben in der jüngsten Zeit Hauptmann ${ }^{7}$ ), Falke und Wetzel u. a. diese Auswertung des inaktiven Serums zumal bei der Untersuchung der Spätsyphilis des Z.-N.-S. empfohlen. Boas ${ }^{3}$ ) hat dagegen geltend gemacht, daß bei Verwendung höherer Serummengen als $0,2(20 \%)$ es in besonderen Fällen zu unspezifischen Hemmungen kommen kann. Er bekämpft daher ihre Verwendung, wie es neben anderen Autoren auch $\mathrm{Ka} \mathrm{up}^{19}$ ) und Lange ${ }^{22}$ ) tun. Lange tritt sogar auch gegen die Aus- 
wertung im Liquor auf, die ja eine unentbehrliche Hilfe in der Liquordiagnostik bietet und überall angewendet wird. Sor $\operatorname{ma~ni~}^{36}$ ) und $\mathbf{K a ~ u ~} \mathbf{p}^{\mathbf{1 9}}$ ) legen, wie auch andere Forscher, das Hauptgewicht auf die richtige Einstellung des Komplements. Lange tut dies ebenfalls; er betont hierbei auch die Notwendigkeit der rïchtigen Herstellung der Hammelblutaufschwemmung. Während Sormani eine Verfeinerung in der Verminderung der Komplementmenge sieht, tritt Ka u p dafür ein, daß die Komplement,einheit" genau bestimmt und dabei die Extrakt- und Serumwirkung berücksichtigt wird; er arbeitet daher mit steigenden Komplement- und konstanten Serum- und Extraktmengen. Auch in den Serumkontrollen werden steigende Alexinmengen verwendet. Er führt ferner an Stelle der Extraktkontrollen Extrakt-Normalserumkontrollen ein und beurteilt das Resultat unter Berücksichtigung der Serumeigenhemmung. Er glaubt auf diese Weise eine erhöhte Empfindlichkeit gegenüber besonders der Originalreaktion erzielen und den Grad unspezifischer Einwirkung messen zu können. Lange kommt auf Grund ähnlicher Utberlegungen in dankenswerten, klaren Auseinandersetzungen zu anderen Resultaten. Er betont, daß die Hammelblutaufschwemmung nur entweder als 5 proz. vom Blutkörperchenzentrifugat oder als 11-12 proz. vom defibrinierten Gesamtblut hergestellt werden darf, wenn man mit den sonstigen konventionellen Größen der Originalmethode arbeitet. Wenn man nun die Amboceptoreinheit mit 10\% Komplement festgestellt hat, so genügt nach Lange zur vollständigen Lösung einer 5proz. richtig hergestellten Hammelblutaufschwemmung bei 4 Amboceptoreinheiten 2,5-3\% Komplement. Diese Dosis bezeichnet Lange als Komplementeinheit. Fügt man nun zum hämolytischen System die Extraktgebrauchsdosis, so muß man, um die Eigenhemmung des Extraktes zu überwinden, 4\% Komplement mehr verbrauchen, im ganzen also 7\%. Lange weist nun weiter nach, daß noch ein Komplementüberschuß von $3 \%$ nötig ist, um die eventuell vorkommenden unspezifischen Bindungen bei Tuberkulose und Carcinom (im ganzen $7-9 \%)$ sowie jene bei Scharlach $(9-10 \%)$ zu überwinden. Er verzichtet dabei auf den Nachweis der Luesseren, die nur im aktiven Versuch oder bei niedrigeren Komplementmengen die WaR. geben, da sie nur 7-10\% Komplement verbrauchen. Erst bei der Verwendung von $10 \%$ Komplement kann man nach Lange eine sichere und spezifische WaR. erhalten. Da nun alle Mengen konventionell aufeinander eingestellt sind, so gelangen wir nach Lange bei Verwendung höherer Serummengen als $20 \%$ wieder in das Gebiet unspezifischer Bindungen. Nun könnte man ja sagen, daß diese Gefahr es nicht voll rechtfertigt, auf die zweifellose Verfeinerung, die man durch die Verwendung höherer Serummengen und die damit einhergehende Vermehrung der Reagine erreicht, zu verzichten, da man ja die in Betracht kommenden zu un- 
spezifischen Bindungen neigenden Erkrankungen leicht auszuschließen in der Lage ist. Aber auch experimentell ließ sich für unsere Methodik der Langesche Vorwurf größtenteils entkräften. Wir arbeiten stets mit einer 5 proz. Aufschwemmung des defibrinierten Gesamtblutes, verwenden 5 Amboceptoreinheiten und $5 \%$ Komplement*). Bei dieser Methodik ließ sich nun feststellen, daß die Komplementeinheit für uns meist 2, seltener 2,5\% Komplement betrug. Bei Einstellung der Gebrauchsdosis eines alkoholischen Luesleberextraktes wurden weitere $1 \%$, sehr selten $2 \%$ Komplement verbraucht. Wurden nun ansteigende Mengen von Komplement in den Versuch mit inaktivem Normalserum in der Dosis von 20 und $50 \%$ eingesetzt, so ergab sich für beide Serumdosen der Komplementverbrauch auch von $3-3,5 \%$ Komplement. Bei Einstellung von Normalliquor war der Komplementverbrauch für $20-50 \% 2,5-3,5 \%$, für $100 \% 3,5-4 \%$ Liquor. Es bleibt also für das inaktivierte Serum noch immer auch bei Anwendung der Serumdosis von $50 \%$ und von $5 \%$ Komplement fast eine Komplementeinheit, zumindest $3 / 5$ derselben zur Beseitigung unspezifischer Bindungen übrig; bei möglichst frischer Bearbeitung der Sera, wie es bei uns üblich ist, liegen die Verhältnisse besonders günstig. Etwas schlechter sind die Bedingungen für den Liquor, doch ist hier ja die Möglichkeit unspezifischer Bindungen geringer; Vorsicht ist eigentlich nur bei akuten infektiösen Meningitiden geboten, und es mögen die von $\mathrm{Zadek}^{42}$ ) und von $\mathrm{Kraemer}{ }^{20}$ ) berichteten unspezifischen Komplementbindungen bei nichtluischer Meningitis auf diesen Faktor vielleicht zurückzuführen sein. Wir haben aber bei unserer Methodik stets sichere Resultate erhalten, die Auswertung des Serums bis $50 \%$ hat uns bei langjähriger Bearbeitung eines sehr großen Materials wertvolle Dienste geleistet und wir glauben, experimentell gezeigt $\mathrm{zu}$ haben, daß dieses Hinaufgehen mit der Serumdosis methodisch a uch berechtigt ist. Wir verdanken aber Lange den Einblick in diese Verhältnisse und hoffen, daß er nach dem eben Gesagten unsere Methodik nicht zu beanstanden hat.

Wenn man aber durch den Vorwurf, durch die Auswertung des inaktiven Serums bis $50 \%$ unmethodisch und unspezifisch zu arbeiten, nicht mehr getroffen werden kann, so beleuchtet diese kleine Modifikation zweifellos eine Verfeinerung, die gerade bei unseren Fällen, wo die Reagine im Serum mit den feinsten einwandfreien Methoden

*) Auch Sonntag ${ }^{35}$ ) stellt seine 5 proz. Hammelblutaufschwemmung aus dem defibrinierten Gesamtblut her. Er hat daher mit 0,05 Komplement fast immer gute Resultate bei Verwendung der $4-5$ fachen Ambceptoreinheit. Wir arbeiten übrigens jetzt vergleichsweise mit obiger Methodik und mit jener, bei der Hammelblutaufschwemmung aus dem Blutkorperchenzentrifugat 5 proz. hergestellt und 10 proz. Komplement verwendet wird. 
gesucht werden müssen, um Blut und Liquor zu vergleichen, notwendig, zumal wenn es sich, wie bei unseren Fällen, um sichere Spätlues des Zentralnervensystems handelt. Wir haben deshalb auch in unseren Untersuchungen die Komplementbindung mit nicht inaktiviertem Serum in Form der Modifikation von M. Stern mitgemacht.

Nachdem wir nun gezeigt zu haben glauben, daß unsere Methodik zum sicheren Nachweise der Reagine geeignet ist, seien ein paar Worte über die Frage der Natur der Luesreagine gestattet. Denn es ist ja von Wichtigkeit, sich darüber klar zu werden, was ein Versagen des Blutes in der Bildung der Reagine zu bedeuten hat.

Wir können a. d. O. nicht ausführlich auf die Geschichte der WaR. eingehen. Bekanntlich ist man von der Annahme einer spezifischen Immunitätsreaktion sowohl wie auch von jener dualistischen, die dem Antigen einen spezifischen und unspezifischen Anteil zuschreibt, größtenteils abgekommen. Für uns kommen daher heute 3 Ansichten in Frage. Weil und Braun ${ }^{41}$ ) haben schon frühe betont, daß die WaR. durch „Reaktionsprodukte gegen körpereigene Zellbestandteile", für die sie aber antikörperartigen Charakter annahmen, hervorgerufen werde. Much und Emden ${ }^{25}$ ) nehmen an, daß die WaR. auf einem Plus von Aminosäure im Blute als Folge des Abbaus parenchymatöser Organe beruhe, daß sie also den direkten Ausdruck einer Gewebsschädigung darstellt. v. Wasserman ${ }^{38}$ ) selbst ist der Ansicht, daß die Reagine nicht im Blute selbst, sondern außerhalb der Blutbahn durçh die Tätigkeit der Körperstellen entstehen. „Die Blutbahn ist eine das Sammelbecken für die seitens des Gewebes als Antwort auf den syphilitischen Defekt gebildeten Reaktionssubstanzen." Als Beweis dafür führt Wassermann an, daß bei Iritis specifica das Kammerwasser positiv reagieren kann, bei negativer WaR. des Blutes. „Dies ist ein springender Beweis dafür, daß die Substanzen, welche die WaR. geben, seitens der Gewebe gebildet werden, woselbst die Spirochäten sitzen." Er erwähnt ferner seine hier schon zitierten Fälle von Paralyse, die er mit Pla ut mitgeteilt hat und bei denen das Serum überhaupt nicht reagierte, während die Lumbalflüssigkeit eine positive Reaktion ergab oder sich ein deutlicher Unterschied der Stärke der WaR. zuungunsten des Blutes gezeigt hatte. „Also ebenfalls ein Beweis, daß bei dieser syphilitischen Erkrankung des Zentralnervensystems die spezifischen Substanzen im erkrankten Organ sich bilden."

Es ist also auch Wassermann nicht mehr Anhänger der Annahme, daß die Luesreagine als Antikörper im immunbiologischen Sinn anzusehen sind; er hat auch von neuem ihre lokale Bildung betont. Nun haben Wassermann und Lange ${ }^{40}$ ) schon im Jahre 1914 versucht, sich ein Bild über die Entstehung der Luesreagine im Liquor zu geben. Sie nahmen an, daß die Rückenmarksflüssigkeit günstigere Verhält- 
nisse für derartige Untersuchungen biete, da im Blute die Gefahr unspezifischer Bindungen bei der Komplementbindung größer sei. Ihre Fragestellung war, ob die Reagine spezifisch mit dem syphilitischen Prozeß etwas zu tun hätten oder ob sie durch Resorption von Organsubstanzen entstünden.

Sie gingen nun so vor, daß sie den Grenztiter der WaR. einer Rückenmarksflüssigkeit bestimmten, hierauf einen Teil derselben scharf zentrifugierten; die uberstehende Flüssigkeit wurde in zwei Teile geteilt (Portion I und II). Von Portion I wurde ebenfalls der Grenztiter bestimmt, Portion II wurde mehrere Stunden bei $56^{\circ}$ gehalten, hierauf ebenfalls der Grenztiter bestimmt. Der zellhaltige Rückstand (Portion III) wurde ebenso wie Portion II der Autolyse bei $56^{\circ}$ ausgesetzt; dann wurde der Grenztiter dieser Portion ebenfalls bestimmt.

Unter 18 Fällen war in 11 (nicht in 12, wie die Autoren mitteilen) der Titer der Portion III gegenüber jenem von II erhöht d. h. bei einer höheren Verdünnung der Flüssigkeit, manchmal war er sogar höher als der der nativen Flüssigkeit. Wassermann und Lange sehen daher in den Lymphocyten die Quelle der die WaR. hervorrufenden Stoffe, und zwar in Lymphocyten, die einen spezifischen Anteil haben.

Ich habe durch Neinha us, der auf dem Felde der Ehre gefallen ist, bereits 1914 ähnliche Versuche anstellen lassen. Ein Unterschied in unserer Methodik gegenüber jener von Wassermann und Lange bestand darin, daß wir Portion II und III bei $37^{\circ}$ autolysieren ließen, sterile Versuchsbedingungen vorausgesetzt. Unter 13 Fällen fand nun Neinha us 10 mal die Titer der Portionen II und III niedriger als jenen des nativen Liquors und der Portion I; in 9 dieser Fälle waren die Titer der Portionen II und III gleich oder fast gleich, in 2 war er bei III niedriger. In den 3 übrigen Fällen war das Verhalten so, daß einmal der Titer der Portion II höher war als jener von III, einmal waren Portion II und III in ihrem Titer höher als der native Liquor und Portion I und untereinander gleich, einmal waren die Titer von Portion I und II höher als jene des nativen Liquors und der Portion I, wobei letzterer etwas höher war als ersterer. Unsere Resultate zeigten also keine Úbereinstimmung mit jenen von Wassermann und Lange. Wenn wir uns dazu noch vergegenwärtigen, daß M. Pa p pe nhei ${ }^{32}$ ) im Jahre 1908 mitgeteilt hat, daß Extrakte von weißen Blutzellen, die durch die Haarseilmethode erhalten worden waren, positive $\mathrm{WaR}$. geben, so sehen wir, daß auch polynucleäre Leukocyten imstande sind, unter Umständen Komplementbindung zu geben. Dazu kommt, daß Spät ${ }^{37}$ ) gefunden hat, daß auch Zellen nicht syphilitischer Herkunft imstande sind, den Titer erhitzter Cerebrospinalflüssigkeiten zu steigern.

So bedeutend also die Versuchsergebnisse von Wassermann und Lange sind, so können wir heute noch nicht sagen, daß die Entstehung der die WaR. hervorrufenden Substanzen im Liquor durch Lymphocyten bewiesen ist. Weitere diesbezügliche Nach- 
untersuchungen an großem Material und mit erweiterter Fragestellung erscheint dringend notwendig.

Die Forschung der letzten Jahre hat sich mehr mit den Vorgängen bei der WaR. beschäftigt; die interessanten Arbeiten von H. Sachs und seinen Schülern, Bruck, Meinicke sowie Hirschfeld und Klingen haben dargetan, daß dem Phänomen der WaR. wie auch den neuen Ausflockungsreaktionen eine physikalische Zustandsänderung zugrunde liegt; wir erfahren aber wenig über die Ursache derselben. Meinic $\mathrm{ke}^{23}$ ) allein hat sich dahin geäußert, daß das Wesentliche im Serum des Syphilitischen nicht die erhöhte Fällbarkeit der Globuline ist, ,,sondern das Auftreten chemisch neuartiger Stoffe, nämlich solcher, die unabhängig von ihrer chemischen Fällbarkeit eine besondere Affinität zu Extraktlipoiden besitzen. Derartige Stoffe weisen im allgemeinen nur die Sera der Luetiker auf. Bei allen anderen Krankheiten haben die Serumstoffe diese Avidität zu Extraktlipoiden nicht schon von sich aus, sondern erhalten sie erst dann, wenn man sie mit ihren spezifischen Antigenen zusammenbringt".

Da wir nun leider die Ansicht von Wassermann und Lange, daß wir die Quelle der die WaR. hervorrufenden Stoffe in Lymphocyten mit spezifischem Ateil, der ja für den Liquor nicht bewiesen ist, zu suchen haben, für die Verhältnisse des Gesamtorganismus nicht verallgemeinern können, trotzdem manche klinische Tatsache dafür sprechen würde, andererseits die Muchsche Lehre ja sehr viel für sich hat, aber in der von $\mathrm{M} \mathrm{uch}$ gegebenen Fassung ,,Ausdruck einer Gewebsschädigung" uns mit den klinisch spezifischen Verhältnissen nicht ganz vereinbar erscheint, so glauben wir den heutigen Erfahrungen am wenigsten Gewalt anzutun, wenn wir als Quelle der WaR. Stoffe ansehen, die der.spezifischen Einwirkung der Spirochäte auf das Gewebe ihre Entstehung verdanken. Daraus folgt auch, daß wir bei positiver WaR. die Añwesenheit von Spirochäten (oder unter Umständen der von ihnen hervörgerufenen spezifischen Stoffe) annehmen müssen.

Dies führt uns noch zu einer weiteren Frage, die zu erörtern wäre: Ist eine Filtration der,Luesreagine aus dem Blut in den Liquor möglich und wie verhält es sich umgekehrt mit dem Úbertritt dieses Stoffes aus dem Liquor in das Blut?

Diese Frage erscheint nach dem heutigen Stand unserer Anschauungen, die einer lokalen Entstehung der Luesreagine das Wort reden, nebensächlich und ist es doch nicht. Unter den früheren Anhängern der Filtrationstheorie müssen wir besonders $Z$ aloziecki ${ }^{43}$ ) nennen, während Hauptmann ${ }^{8 a}$ ) 1914, also zu einer Zeit, wo der frühere Wassermann-Pla utsche Standpunkt verlassen schien, für die lokale Entstehung der die WaR. hervorrufenden Stoffe auftrat. Die Filtrationstheorie ist auch heute nicht vollkommen von der Hand zu 
weisen; sie gilt aber nur für besondere Fälle. So bildet sie die einzige Erklärung für die von sieben Autoren beobachtete Erscheinung, daß Luiker mit positiver WaR. im Blute beim Auftreten einer infektiösen nichtluischen Meningitis eine positive WaR. im Liquor aufweisen, die mit dem Abklingen der meningitischen Erscheinungen wieder schwindet. Hier können wir uns zur Erklärung nur vorstellen, daß infolge der stark erhöhten Permeabilität der Meningealgefäße (am besten demonstriert durch die Hämolysinreaktion nach Weil und Kafka) ein Übergang der Luesreagine aus dem Blut in den Liquor stattfindet. Es wäre von großem Interesse, die Rückenmarksflüssigkeiten solcher Fälle genau zu untersuchen, besonders nach der Richtung der Spaltung der Eiweißkörpir u. ähnl. Die Filtration spielt aber nur für die erwähnten Fälle eine Rolle. Sind die Meningen nicht affiziert - weder luisch noch nicht-luisch - dann finden wir auch keine positive WaR. der Rückenmarksflüssigkeit. Bei der frühluischen Meningitis ist die Permeabilität der Meningealgefäße meist nicht erhöht; die eventuell vorkommende positive WaR. ist die Folge der syphilitischen Meningealerkrankung selbst; dasselbe gilt für die Gehirnsyphilis und die Paralyse, wo ja die lokale Erkrankung des Zentralorgans und der Meningen die positive WaR. des Liquors begründet. - Was nun den umgekehrten Weg Liquor $\rightarrow$ Blut betrifft, so wissen wir, daß Stoffe, die in den Liquor eingeführt werden, nach kurzer Zeit im Blute und Harn nachweisbar sind. Dafür sprechen auch Versuche von $\mathrm{Nast}^{26}$ ). Wie haben wir uns nun jene Fälle zu erklären, bei denen eine stark positive WaR. der Rückenmarksflüssigkeit, aber negative WaR. des Blutes besteht Als Erklärung kann man annehmen, daß die im Z.-N.-S. erzeugten Reagine, die z. T. ins Blut übergehen, in diesem großen Reservoir so verdünnt werden, daß sie sich unserem gewöhnlichen Nachweis entziehen, zumal wenn sie im Liquor in nicht zu großer absoluter Menge vorhanden sind. Eine andere Annahme, daß im Blute solcher Kranken hemmende Stoffe für die WaR. vorhanden sind, hat nicht viel für sich. Viel häufiger aber wird der Fall vorhanden sein zumal bei der Paralyse, daß aus dem Liquor genügend Reaktionsstoffe (und Spirochäten) in das Blut übergehen, um dort eine positive WaR. hervorzurufen*).

Noch eines Einwandes müssen wir gedenken, bevor wir die Folgerungen auf das Paralyseproblem ziehen: belehrt uns überhaupt der bei der Lumbalpunktion erhobene Befund der Rücken-

*) Dem Dermatologen fällt oft auf, daß in Fällen, wo die WaR. im Blute stark und beeinflußtar ist, Verdacht einer Paralyse besteht. In solchem Falle ist aber die Liquorreaktion noch stärker und die Unbeeinflußbarkeit der WaR., die noch mit dem Nichtvorhandensein syphilitischer Veränderungen außerhalb der Z.-N.-S. parallel geht, spricht für die Abstammung der Reagine aus dem Z.-N.-S. 
marksflüssigkeit über den Zustand des ganzen Liquors? 0 . Fischer hat bekanntlich festgestellt, daß die Pleocytose der meningealen Infiltration des betreffenden Rückenmarksabschnittes entspricht. Wenn auch nun Fischers Befunde generell und vollinhaltlich zur Wahrheit bestünden, was noch nicht bewiesen ist, so spielte dieses Faktum für unsere Utberlegungen keine große Rolle, da wir immer darauf hingewiesen haben, daß zwar die Feststellung, ob Pleocytose oder nicht von Wichtigkeit, eventuell noch die allgemeine Angabe ihrer Stärke, daß aber weitere Folgerungen aus der Zellzahl der Rückenmarksflüssigkeit unstatthaft sind, schon deshalb, weil die Pleocytose das variabelste Symptom unter den krankhaften Liquorveränderungen darstellt. Für die Globulinvermehrung, ausgedrückt in positiver Phase-I-Reaktion habe ich schon a. a. St.*) bewiesen, daß sie in verschiedenen Höhen nur selten und dann sehr geringe Differenzen aufweist; für die WaR. habe ich Unterschiede in verschiedenen Höhen so gut wie gar nicht nachweisen können. Wir können also sagen, daß uns mit A usnahme der Pleocytose die Ph. I und WaR. der bei der Lumbalpunktion entnommenen Flüssigkeit über den pathologischen Zustand des ganzen Liquors informieren, wobei, wenn überhaupt, nur geringe quantitative Differenzen nachweisbar sind und Ausnahmen sehr selten vorkommen.

Gehen wir nun zu unserem Paralysematerial über. Wir haben gefunden, daß in rund $20 \%$ der Fälle einem stark positiven Liquorbefund eine negative oder fast negative WaR. des Blutes gegenübersteht. Wir müssen natürlich annehmen, daß sich dieses Verhältnis erst entwickelt, daß also in einem Stadium oder Zeitraum die WaR. des Blutes positiv war**). Wir sehen ja diese Tendenz der Blutreaktion zum Negativwerden in vielen Fällen unserer Beobachtung. Bei unserer Annahme der lokalen Bildung der Luesreagine ist die Folgerung naheliegend, daß sich in solchen Fällen Spirochäten nur im Gehirn befinden, nicht aber im übrigen Körper und daß eine Propagation der Parasiten aus dem Zentralorgan in den Körper, wenn überhaupt, nur in geringem Maße statthat. Tatsächlich finden wir ja in den meisten Fällen von Paralyse bis auf die häufige Mesaortitis syphilitica keine syphilitischen Prozesse und auch keine Spirochäten außerhalb des Zentralnervensystems. Wir könnten aber auch zu der Mutmaßung kommen, daß die Gewebsreaktion des Körpers in solchen Fällen versagt und ihr Ausdruck, die WaR., daher in solchen Fällen allmählich schwindet. Trotzdem letztere Anschauung nach dem, was wir oben über die Natur der WaR.

*) Diese Zeitschr. 13 u. 15.

**) Für diese noch nicht geklärte Frage ist die Arbeit von Edel und Piotrowski (Neurol. Centralbl. 1916. S. 166) wertvoll, die bei beginnender Paralyse nur positive WaR. im Liquor bei negativer im Blute feststellen.

Z. f. d g. Neur. u. Psych. O. LVI. 
gesagt haben, nicht wahrscheinlich ist, wollen wir untersuchen, welche von beiden Ansichten zu Recht besteht oder ob vielleicht beide nebeneinander wirksam sind.

Bezüglich der Reaktion des Zentralnervensystems möchte ich auf Untersuchungen von A. Jako b ${ }^{12}$ ) nachdrücklich hinweisen. Er betont an der Hand eines großen Materials ausdrücklich, daß wir im Gegensatz zur Gewebsreaktion der Lues, die sich in Form von Granulomen bei verhältnismäßig geringem Spirochätengehalt äußert, bei der Paralyse nur eine ,unspezifische, diffuse kleinzellige Entzündung und Parenchymzerfall “ sehen, trotzdem ,offenbar zu gewissen Krankheitszeiten eine Unmenge Parasiten das Gehirn überschwemmen". Die ,so häufig bei Paralyse sich findenden gummösen Bildungen im Gehirn sind als ungenügende spezifische Gewebsreaktionen im Kampfe gegen die Spirochäte aufzufassen".

Wir haben uns bei dieser Gelegenheit vorzuhalten, daß bei der Paralyse, wie ich immer betont habe, der Liquorbefund dadurch charakteristisch ist, daß die entzündlichen Reaktionen mit der WaR. nicht gleichen Schritt halten, da $\$$ vielmehrin der Regel einerintensiven WaR. mittelstarke oder schwache entzündliche Reaktionen gegenüberstehen. Im Gegensatz dazu sehen wir bei der frischen Gehirnsyphilis intensivste entzündliche Liquorerscheinungen neben mittelstarken oder schwachen biologischen. Wir haben also hier ein Analogon zu A. J a ko bs histologischem Befund. Ferner haben die Liquorreaktionen der Gehirnsyphilis die Tendenz zum Negativwerden, während die Befunde der Rückenmarksflüssigkeit in typischen Fällen von Paralyse in allen Stadien absolut und relativ mit geringen Schwankungen gleich bleiben, auch wenn spezifisch behandelt wird (abgesehen von der endolumbalen Salvarsantherapie). In diesem Punkte hat also die Paralyse eine gewisse Ähnlichkeit mit der malignen Lues. Wir müssen uns weiter der Tatsache erinnern, da $\beta$ die intracutane Injektion von abgetöteten Spirochäten bei Paralyse und Gehirnsyphilis ein verschiedenes Resultat ergibt. Wie ich ${ }^{18}$ ) in Ubereinstimmung mit den meisten Autoren, die mit der Luesinreaktion nach Noguchi gearbeitet haben, beobachten konnte, sehen wir bei der Paralyse nur $52 \%$ positiver Impfresultate gegenüber $90 \%$ bei der Lues cerebri, $100 \%$ bei der Tabes. Der Vergleich fällt aber noch mehr zum Nachteil der Paralyse aus, wenn wir die sicher positiven Reaktionen der Stärke nach miteinander vergleichen: bei der Paralyse $17 \%+, 4,2 \%++, 2,1 \%+++$, dagegen bei der Gehirnsyphilis $30 \%+$ und $30 \%+++$ Ergebnisse! Die positiven Impfresultate bei Lues cerebri werden bei spezifischer Behandlung stärker, die bei Paralyse nicht. Wir können also ganz allgemein sagen: die Paralyse weist eine bedeutend schwächere celluläre Abwehrreaktion a uf als die Lues cerebri. 
Es scheint hier der Ort zu sein, um auf Untersuchungen von $\mathrm{H} . \mathrm{Mu} \mathrm{ch}^{24}$ ) über Lues und Paralyse einzugehen. Er faßt die Entstehung der Paralyse so auf, daß der Körper in diesem Stadium nicht mehr reaktionsfähig und überempfindlich ist. Ausgehend von der bekannten Tatsache, daß besonders leicht verlaufende Fälle von Syphilis zur Paralyse prädestinieren, sagt $\mathrm{Much}$ : ,Bei ihnen setzt von vornherein keine große Immunität ein, daher Ausbleiben der sekundären und tertiären Erscheinungen, die an und für sich schwache Uberempfindlichkeit verschwindet bald gänzlich, der Körper wird unter besonderen Bedingungen reaktionsunfähig: Es kommt zu Tabes und - Paralyse." Diese Ansicht M u ch s hat viel Bestechendes für sich, enthält aber manche große Lücke.

Wir müssen, um dem Problem näherzukommen, nun zusammenfassend die Frage beantworten: wie steht es mit den Abwehrreaktionen des Körpers und des Gehirns beim Ausbruch und während des Bestehens der Paralyse? Für die Insuffizienz der Abwehrvorgänge im Gehirne sprechen die histologischen Befunde und das Liquorbild. Dafür, daß die Abwehrvorgänge auch im Körper ungenügend waren und sind, spricht die eben zitierte häufige „Benignität" der frühen Luesstadien (II und III), ferner das Ergebnis der Luetinimpfungen. Die Tendenz der WaR. im Blute der Paralytiker negativ zu werden, können wir nicht ohne weiteres unter die erlahmenden Gewebsreaktionen einordnen; man käme dann in Widerspruch mit den Verhältnissen beim Gehirn, wo ja trotz ungenügender Abwehrreaktionen die WaR. stark positiv ist und bleiben kann. Wie wir schon angedeutet haben, sind diese Tatsachen wohl so zu erklären, daß wir nur im Gehirn eine direkte Einwirkung der Spirochäten a uf das Gewebe und als Folge eine positive WaR. anzuneh men haben, während im Körper Spirochäten oder Reaktionsstoffe nur vorhanden sind, soweit sie aus dem Gehirn stammen. Der körperliche Rückgang ist nach unserem jetzigen Stande des Wissens ja als Folge der Gehirnerkrankung anzusehen.

Wenn wir heute nun wissen, daß das Zentralnervensystem der Syphilitiker in der großen Mehrzahl der Fälle schon im Sekundärstadium syphilitisch erkrankt, so werden wir gerade auç auf Grund der obigen Feststellungen in diese Zeit den ersten Beginn der künftigen Paralyse verlegen müssen. Nehmen wir an, daß im frischen Sekundärstadium eine bestimmte Anzahl von Spirochäten in das Zentralnervensystem eindringt, eine bestimmte Anzahl im übrigen Körper zurückbleibt. Die Infektion sei nun unter gegebenen Umständen nicht genügend stark, um den Körper zu besonders intensiven Abwehrmaßnahmen zu zwingen; vielleicht genügt schon eine Steigerung seiner normalen Immunkräfte dazu. Es resultiert ein mildes Sekundärstadium; das Tertiärstadium 
bleibt ganz aus, auch die damit parallel gehende Gewebsumstimmung. Die Spirochäten im Gehirn finden hier keine besonders erheblichen Abwehrmechanismen vor; sie bleiben größtenteils erhalten, weil die zu ihrer Abtötung nötigen starken humoralen Abwehrkräfte des Körpers versagen. So können sich die Spirochäten in der Gehirnsubstanz einnisten; sie führen hier Kämpfe mit den etwa vorhandenen humoralen Antikörpern und den ungenügenden cellulären Abwehrreaktionen des Gehirns, in dem sie Sieger bleiben und Rezidivstämme bilden; so ist auch die Möglichkeit für ihre diffuse Verbreitung gegeben. Schließlich sind die durch die Spirochäten gesetzten krankhaften Veränderungen des Gehirns so weit gediehen, daß die Paralyse klinisch in Erscheinung tritt. Aber der biologische Gewebskampf kann auch nach ihrem Ausbruche weiter toben; in den Anfällen der Paralytiker und anderen Paroxysmen haben wir das Resultat solcher Kämpfe zu erblicken, wie uns, abgesehen von anderen Utberlegungen, die schönen histologischen Arbeiten von $\mathrm{Jakob}$ und $\mathrm{J}$ ahnel lehren.

Das Wesentliche der eben vorgetragenen Hypothese wäre die Vorstellung, daß sich bei der Paralyse gewissermaßen eine Spirochätose des Gehirns entwickelt, ohne daß der übrige Körper sich darum wesentlich kümmert, während bei der Lues cerebri die krankhaften Vorgänge in Gehirn und Körper parallel gehen und miteinander zusammenhängen, so daß die Lues cerebri gewissermaßen einen Teil der Gesamtlues des Körpers bildet. Da überall in der Natur fließende Übergänge bestehen, werden solche zwischen den eben genannten beiden Extremen vorhanden sein und die Übergangs- und atypischen, wie Mischfälle erklären. Bei der Paralyse wird dann der klinische Verlauf abhängig sein von dem Ergebnis des biologischen Gewebskampfes und der Spirochätenwirkung, vor allem wird hier die Quantität der im Gehirne ständig wirksamen Spirochäten eine Rolle spielen, so daß wir von der furibunden letal verlaufenden Paralyse zur Anfallsparalyse, dann weiter zur lange dauernden Paralyse mit akuten Schüben bis zur einfachen stationären Paralyse eine zusammenhängende Reihe von Krankheitsbildern haben, bei denen obige Momente von einer Gruppe zur anderen abnehmen. Dafür sprechen vor allem die.Ergebnisse der Histologie; aber auch die Tatsachen, daß die Liquorreaktionen in der obengenannten Reihe absteigend schwächer bis negativ werden, bilden eine Bestätigung dafür und werden andererseits durch die geschilderten Vorgänge erklärt.

Wir hatten uns also vorzustellen, daß die Abwehrmaßnahmen des Körpers bei der Paralyse deshalb so schwach sind, weil der Körper nie unter genügender Spirochätenwirkung gestanden ist (oder nicht genügend reagiert hat) und auch zur Zeit des klinischen Ausbruches der Erkrankung 
keine oder fast keine Parasiten in ihm vorhanden sind. Das Gehirn allein ist und bleibt der Spirochätenträger, da es gegen die Parasiten größtenteils auf seine eigenen Abwehrkräfte angewiesen war und ist, die bei dem ganzen A ufbau des Organes ungenügende sind. Die positive Blutreaktion nach Wassermann, die wir bei der Paralyse oft sehen, ist hervorgerufen durch spezifische Abbauprodukte der Spirochätenwirkung auf das Gewebe (z. T. vielleicht auch durch Spirochäten selbst), die aus dem Gehirn bzw. dem Liquor in das Blut übergehen. Ist die Spirochätenwirkung im Gehirn eine stürmische, so bleibt die WaR. des Blutes, zumal in schweren kurzdauernden Fällen, wegen der starken Úberschwemmung mit aus dem Gehirn stammenden Luesreaginen positiv; sie zeigt aber in der Mehrzahl der Fälle die Tendenz zum Schwächerwerden, wenn die ,aus dem Gehirn stammenden Stoffe an Menge abnehmen und durch die Verteilung im ganzen Blutgefäßsystem stark verdünnt werden.

Es wäre dann noch die Kardinalfrage zu erörtern: woher kommt es, daß im Frühstadium der Lues diese eigenartige Verteilung und Wirkungsweise der Spirochäten statthat? Eine ganze Reihe von Umständen wird hier als Ursache anzunehmen sein: Eintritt von quantitativ geringfügiger Spirochätenmenge in den Organismus, Langsamkeit des Ưbertrittes, wobei in beiden Fällen ein Teil der Parasiten in das Gehirn eindringt. Schließlich kann diese Aussaat ins Gehirn durch besondere Bedingungen sehr stark sein. In allen diesen Fällen wird die durchschnittliche Reaktionsfähigkeit des Körpers genügen, der nur geringe humorale und celluläre Abwehrkräfte auszurüsten hat, um der Spirochäten Herr zu werden. Ist die angeborene Reaktionsmöglichkeit des Körpers auf die Parasiten besonders schwach, dann wird auch eine größere Spirochätenaussaat im Körper obige Verhältnisse hervorrufen können, vorausgesetzt immer, daß Spirochäten in das Gehirn übertreten. Eine abnorm starke Reaktionsbereitschaft des Körpers gegenüber den Spirochäten wird dagegen auch bei geringer Spirochätenmenge und -wirkung so starke Abwehrvorgänge provozieren, daß die Gefahr der Paralyse gering ist. So sehen wir ja auch, daß die mit schweren Luesformen reagierenden Rassen nicht zur Paralyse disponiert sind.

So können eine ganze Reihe von Faktoren bei unserer Anschauung der Pathogenese der Paralyse eine Rolle spielen. Wir haben unsere nicht in allen Teilen neue Hypothese hier ausführlicher besprechen zu müssen geglaubt, weil sie sich am besten den vielen neuen Tatsachen der Histologie, Serologie und Klinik anpaßt und u. E. die von A.J a ko b vorwiegend auf Grund anatomischer Feststellungen präzisierte Auffassung der Paralyse als ,,maligner Lues des Gehirns" zu ergänzen in der Lage ist.

Natürlich muB eingehendes Arbeiten mit der Luetinreaktion auch nach der Richtung der Partigene Muchs, vor allem aber der Ausbau 
294 V. Kafka: Atypische serologische Befunde bei Paralyse und ihre Bedeutung.

weiterer echter Immunitätsreaktionen der Syphilis z. B. der Agglutinaton der Spirochäte ergeben, ob für die oben geäußerten Anschauungen sich auch präzise experimentelle Grundlagen schaffen lassen.

\section{Literaturverzeichnis.}

l. Bergel, Berliner klin. Wochenschr. 1919, Nr. 39.

2. Binswanger, Neurol. Centralbl. 1910, S. 1278.

3. Boas, Die Wassermannsche Reaktion usw. S. Kargerer. Berlin 1914.

4. Eskuchen, Die Lumbalpunktion usw. Urban und Schwarzenberg. Berlin und Wien 1919.

5. Forster, Monatsschr. f. Psych. 38, 162. 1915.

6. Friedemann, U., Zeitschr. f. Hyg. 67, 279. 1910.

7. Hauptmann, Deutsche Zeitschr. f. Nervenheilk. 42, 240. 1911.

8. - Monatsschr. f. Psych. 42, 349.

8a. - Deutsche Zeitschr. f. Nervenheilk. 51, 314.

9. Holzmann, Wiener äzrtl. Standeszeit., Mai 1911.

10. - Neue deutsche Chirurgie 12, Teil.II.

11. Jacobsthal, Hamb. ärztl. Verein 1919.

12. Jakob, A., Zeitschr. f. d. ges. Neur. u. Psych. 52, 17. 1919.

13. - und Kafka, Archiv f. Psych. 51, 3. 1913.

14. Kafka, Verhandl. der Ges. d. Nervenärzte. 7. Jahresvers. Breslau 1913.

15. - Jahreskurse f. ärztl. Fortbild. Maiheft 1918.

16. - Med. Klin. 1913, Nr. 10.

17. - Münch. med. Wochenschr. 1915, Nr. 4.

18. - Berliner klin. Wochenschr. 1915, Nr. 1.

19. Ka u p, Münch. med. Wochenschr. 1917, Nr. 34.

20. Kraemer, Münch. med. Wochenschr. 1918, Nr. 41.

21. Kromayr und Trinchese, Med. Klin. 1912, S. 1670.

22. Lange, Zeitschr. f. Immunitätsf. 26. 1917.

23. Meinicke, Munch. med. Wochenschr. 1917, Nr. 51, S. 1644.

24. Mu ch, Die Immunitätswissenschaft usw. II. Aufl. Kabitzsch. Würzburg 1914

25. - und Emden, Hamb. ärztl. Verein 17. III. 14. Ref. Münch. med. Wochensehr. 1914, S. 271.

26. Nast, Dermatol. Zeitschr. 1919, S. 587.

27. Neue, Deutsche Zeitschr. f. Nervenheilk. 50, 311. 1914.

28. - und Vorkastner, Monatsschr. f. Psych. 34, 117. 1913.

29. Nonne, Deutsche Zeitschr. f. Nervenheilk. 42, 201. 1911.

30. Pla ut, F., Berliner klin. Wochenschr. 1907, 144.

31. - Monatsschr. f. Psych. 22, 95. 1907.

32. Pappenheim, M., Deutsche Zeitschr. f. Nervenheilk. 36. 1908.

33. Pighino, Riforma med. 25, 67. 1909.

34. Rost, Dermatol. Zeitschr. 23, 354. 1916.

34a. Schönhals, Monatsschr. f. Psych. 29, H. 2.

35. Sonntag, Die Wassermannsche Reaktion usw. Julius Springer. Berlin 1917.

36. Sormani, Zeitschr. f. Immunitätsf. 1911, S. 243.

37. Spät, Wiener klin. Wochenschr. 1914, Nr. 26.

38. v. Wassermann, Deutsche med. Wochenschr. 1918, Nr. 33.

39. - und Pla ut, ebenda 1906, Nr. 44. S. 1769.

40. - und Lange, Berliner klin. Wochenschr. 1914, Nr. 11, S. 527.

41. Weil und Braun, Wiener klin. Wochenschr. 1908 und 1909.

42. Zadek, Münch. med. Wochenschr. 1918, Nr. 51.

43. Zaloziecki, Arohiv f. Hyg. 80, 196. 1913. 